Chapter 13

\title{
Peculiarities of Paediatric Digestive Endoscopy
}

\author{
Marco Gasparetto and Graziella Guariso \\ Additional information is available at the end of the chapter \\ http://dx.doi.org/10.5772/52523
}

\section{Introduction}

1.1. What is the role of paediatric endoscopy nowadays? Which are the main indications and contra-indications?

An increased knowledge of normal and pathologic endoscopic patterns in paediatric patients has been increasing in the last decades.

Besides, the availability of flexible instruments with narrow diameter and elevate qualitative resolution allows Paediatric Gastroenterologists to investigate small infants too.

An adequate setting including endoscopic equipment, endoscopic room, support area and dedicated caregivers is fundamental to perform appropriate procedures.

Diagnostic endoscopy comprehends fiber-endoscopy, capsule endoscopy, confocal microendoscopy and echo-endoscopy.

\section{Roles of Digestive Endoscopy}

- Visualisation of the mucosa;

- Evaluation of architecture and vascularisation;

- Evaluation of mucosal secretions;

- Availability to take biopsy samples for histological examination with optic microscopy, ultra-structural examination with electronic microscopy, cultures, CRP methods, dissecting microscopy, chromo-endoscopy, vital staining, enzymatic studies, brushing;

- Endoscopic treatments.

Functions of Digestive Endoscopy 
- Morphologic diagnosis of structural congenital and acquired alterations (optic microscopy, immune-histochemistry, electronic microscopy, confocal microendoscopy, brushing);

- Identification of infective processes (CRP techniques of molecular biology) and cultural examination;

- Morphological, chemical and microbiological evaluation of endoluminal secretions;

- Endoscopic treatment in case of gastrointestinal bleeding, varices, polyps, stenoses, tumors.

\section{Appropriateness. Indications and contraindications to endoscopic examinations [1-2]}

An endoscopic exam is indicated when the expected benefits (longer life survival, pain contention, reduction of anxiety, increase in functional capacity) exceed the potential negative consequences (mortality, morbidity, anxiety, pain, disability).

An endoscopic exam is necessary when it is unavoidable and mandatory for the care of the patient.

\section{Signs and Symptoms of Indication for Upper Gastrointestinal (GI) Endoscopy}

- GI bleeding;

- Disphagia, odinophagia, persistent feeding refusal, persistent chest pain;

- Upper abdominal pain with signs and symptoms suggesting organic diseases (red flags);

- Suspect of peptic disease;

- Persistent vomit;

- Suspected alterations at upper GI imaging;

- Suspected caustic ingestion;

- Iron deficiency anaemia.

Pathologic Conditions for which Diagnostic Upper GI Endoscopy is indicated:

- Peptic esophagitis, hemorrhagic gastritis, peptic ulcers in stomach, bulbus and duodenum;

- Gastrointestinal opportunistic infections i.e. Cytomegalovirus, Fungi;

- Eosinophilic esophagitis;

- Caustic ingestion;

- Atrophic gastritis;

- Helicobacter pylori (HP) gastritis;

- Coeliac disease;

- Inflammatory bowel disease (IBD) with localisation at the upper GI tract; 
- Patients with liver cirrhosis, disphagia, malnutrition, oesophageal varices;

- Congestive gastropathy;

- Chronic diarrhoea of unknown nature;

- Structural alteration of the mucosa (Microvillus Inclusion Disease, Tufting Enteropathy);

- Benign or malignant lesions in common bile duct or duodenum;

- Graft Versus Host Disease (GVHD) after bone marrow transplantation;

- Lymphoproliferation after organ transplantation i.e. EBV-related gastric lymphoma after liver transplantation.

Pathologic Conditions for which Therapeutic Upper GI Endoscopy is indicated:

- Polypectomy;

- Treatment of oesophageal varices;

- Placement of ostomies;

- Treatment of GI bleeding (i.e. bleeding ulcers) non responsive to medical therapy;

- Removal of foreign bodies;

- Oesophageal stricture.

Absolute Contraindication to Upper GI Endoscopy

- Suspect of Gastrointestinal Perforation.

Relative Contraindications to Upper GI Endoscopy

- Non complicated gastro-oesophageal reflux;

- Functional uncomplicated abdominal pain;

- Congenital hypertrophic stenosis of the pylorus;

- Isolated spasm of the pylorus;

- Follow-up controls for ulcers, mucosal abnormalities, Barrett oesophagus;

- Surveillance of benign healed lesions.

Upper GI endoscopy is not appropriate for all children with dyspeptic symptoms, but only for cases [3]:

- With a family history of peptic ulcer and/or HP infection;

- Over 10 years of age;

- With symptoms persisting for more than 6 months;

- With symptoms severe enough to affect activities of daily living; 
Pathologic Conditions for which Diagnostic Lower GI Endoscopy is indicated:

- Inflammatory bowel disease (IBD);

- Infective colitis;

- Allergic colitis;

- Neutrophil disfunction associated colitis i.e. Glycogenosis;

- Immune mediated diseases;

- Vascular abnormalities (venous ectasia secondary to portal hypertension, angiodysplasia, haemangiomas, vasculitis);

- Polyps and polyposes (juvenile polyps, adenomatous polyps, hyperplastic polyps, hamartomatous polyps, hereditary polyposic syndromes as Peutz-Jeghers Syndrome, Cowden Syndrome);

- Pseudopolyps of the colon;

- Neoplastic lesions i.e. leiomyosarcoma, lymphoma, carcinoma;

- Screening of displasia;

- Surveillance after bowel transplantation (rejection, complications);

- Obscure iron deficient anaemia;

- Structural alteration of the mucosa (Microvillus inclusion disease, Tufting enteropathy);

- Chronic diarrhoea of unknown nature;

- Suspect of filling defects or stenoses at radiographic-ultrasonographic images;

- Rectal trauma;

- Necessity of ileal or colonic bioptic samples.

Pathologic Conditions for which Therapeutic Lower GI Endoscopy is indicated:

- Polypectomy;

- Post-polypectomy complications;

- Mucosal resections;

- Ablation of vascular malformations (i.e. Dieulafoy Lesion);

- GI bleeding (i.e. Bleeding ulcers);

- Placement of percutaneous ostomies;

- Dilatations of colonic stenoses;

- Removal of foreign bodies;

Absolute Contraindications to Lower GI Endoscopy 
- Suspected intestinal perforation;

- Severe acute colitis with toxic megacolon;

\section{Relative Contraindications to Lower GI Endoscopy}

- Acute self-limiting diarrhoea;

- Gastrointestinal bleeding with demonstrated origin at the upper GI tract;

- Recent intestinal resection;

- Irritable bowel syndrome;

- Chronic abdominal pain without significant morbidity;

- Simple constipation and encopresis.

\section{The endoscopic technique in the paediatric patient: How to manage the child from pre-anestesia to the awakening}

\subsection{Upper gastrointestinal endoscopy [4]}

Upper gastrointestinal endoscopy is a diagnostic instrumental examination which allows the physician to explore oesophagus, stomach, bulb and the first portions of duodenum.

The endoscope is a long thin flexible tube containing optic fibres. Paediatric endoscopes have diameters between 5.7 and $8 \mathrm{~mm}$. An axial vision is provided.

For safety reasons, it is important for the child not to introduce solid foods since the preceding midnight whereas clear liquids (i.e. water, tea) are permitted until three hours before the procedure.

A peripheral cannula has to be placed before the exam, in order to administer in vein liquids and drugs for sedation. It will be removed after the child's awakening and after he/she will have recovered oral hydration.

An anesthetic cream will be placed in the site of venous puncture, to decrease the intensity of pain feeling.

While waiting for the procedure, the child can look to videos, listen to music or play, supported by the parents as well as by the trained staff of the endoscopic room.

To begin the exam, the child is placed on a left lateral position. The head is kept slightly lifted and inflected, in order to ensure the maximum extent of the hypo-pharynx. A mouthpiece is placed between the teeth to introduce the instrument avoiding lesions in the mouth.

The introduction of the instrument represents the most delicate part of the exam and can be performed in two ways: under strict visual control (visualisation of larynx, glottis, epiglottis 
and vocal chords at hours 12; visualisation of cricoid cartilage and cricoid-pharyngeal muscles in the back at hours 6) or with blind finger-directed intubation.

In case of erroneous intubation of the upper respiratory ways, the immediate removal of the instrument is indicated.

The normal oesophageal mucosa is pink; Z-line represents an important referral marker of the passage between oesophageal and gastric mucosa (more red coloured).

Just under the $\mathrm{Z}$ line, the oesophageal-cardiac junction appears as the confluence of mucosal plicae obliterating the lumen. Insufflation permits to overcome the cardias and enter the stomach where a sudden reduction in brightness due to the dispersion of light into the gastric cavity is observed. The pylorus need to be well visualised and overcome to enter the duodenum through an axial rotation of $90^{\wedge}$ clockwise.

Biopsies can be taken in the return phase of the procedure. Once having reached back the gastric cavity, the manoeuvre of back-vision can be performed to visualise the gastric fundus and the oesophageal-gastric junction (an axial clockwise rotation of $180^{\wedge}$ is required).

During the whole exam, the child is connected to a monitor for his/her vital parameters (heart rate, respiratory rate, oxygen saturation and arterial pressure) to be checked. Parents are asked to leave the room once the deep sleep has begun. They will come back inside the room at the awakening of the child, soon after the procedure has been completed.

During sedation, the endoscopist introduces the instrument through mouth, oesophagus, stomach bulb and duodenum. On a monitor, the upper GI tract mucosa being explored is visible. An appropriate orientation of the instrument needs to be maintained to obtain a real disposition of the features visualised on the monitor. The endoscopic vision is described using clock hands as spatial referral. Bioptic samples can be collected through appropriate pincers and can be sent to histological-microscopical or cultural analysis by the Pathologist and/or by the Microbiologist.

Upper GI endoscopy within its complexity offers a high diagnostic accuracy. It allows to study numerous characteristics of diseases (localisation, extension, disease activity, type of mucosal damage) and offers therapeutic possibilities too.

Upper GI endoscopy lasts 10-15 minutes but the total time for the procedure is longer, taking into consideration the initial preparation and the duration of awakening.

The Upper GI endoscopy is a safe procedure. Complications as perforation and bleeding are exceptional. Their incidence is extremely low within the paediatric population and is mainly connected to severe diseases.

The parent and the child are finally accompanied to their ward waiting for the child to be completely awaken so that he/she can start drinking. Soft and fresh or tepid tempered foods are subsequently proposed. A final clinical evaluation will be effectuated before discharge.

\section{Lower Gastrointestinal Endoscopy [4]}

Ileum-colonoscopy is an instrumental examination aimed to study the whole large bowel starting from its distal segment (the rectum) up to its proximal part (the cecum) passing 
through sigma, descendant colon, transverse colon and ascendant colon. Once the colonoscope has arrived to the cecum, the last tract of small bowel (terminal ileum) is also explored up to its $10-30 \mathrm{~cm}$ (ileal intubation).

The colonoscope is a tubular instrument provided with a video-camera and its diameter is calibrated according to the dimensions of the child. The images of the intestinal mucosa examined are viewed on a monitor being placed in front of the endoscopist.

The instrument is also equipped with a channel through which water can be introduced in order to clean any bowel content. Air can also be insufflated to distend intestinal oxbows and better introduce the instrument.

An aspirator can remove secretions and faecal remnants which prevent a complete visualisation of the mucosa. Other operative tools comprehend small pincers to collect intestinal biopsies to be analyzed by the pathologist for the histological examination, as well as therapeutic instruments (i.e. tolls for polipectomy or haemostasis).

The patient is initially placed on the left lateral position or supine. The inferior limbs are kept inflected. This position is the most approved by paediatric endoscopists because it allows the manoeuvres of abdominal compression as well as the evaluation of the trans-illumination signal thus detecting the position of the endoscope.

A lubrification of the instrument tip as well as of the anal region is effectuated before introducing the endoscope into the rectum, which is examined through a direct linear progression. Once the sigma has been reached, alternated up and down movements of the tip (hooking technique) are necessary to overcome the angle and to avoid the formation of a loop named "alpha-loop". A concomitant compression on the left abdominal quadrants is required.

Once the splenic impression is visualised from the lumen, a $180^{\wedge}$ downward rotation has to be performed to proceed into the transverse colon and to avoid any loop formation. Parallel abdominal compressions are also needed for the manoeuvre.

The transverse and ascendant colon are differently shaped, the former being triangular whereas the latter circular.

The reaching of the cecal extremity is recognizable for the visualisation of the Bauhin valve and of the appendicular lumen. A transillumination in the right iliac quadrant is also visibile.

At the level of the valve, the circular plicae are more pronounced; a $45^{\wedge}$ leftward rotation is required with a mild insufflation to dilate the valve and reach the lumen of the terminal ileum. Abdominal compression or the mobilisation of the patient can be of help for the manoeuvre.

Peyer's plaques are visible at the level of the terminal ileum which presents a circular shape with thickened mucosa. 
The return phase need to be conducted with a carefull circular examination of the mucosa, in order to visualise any possible lesion. Bioptic samples can be taken at any examined segment.

A retro-vision manoeuvre can be performed at the rectum through a downword $180^{\wedge}$ rotation to visualise the anal channel and sphincter from above.

Ileum-colonoscopy within its complexity offers an elevate diagnostic accuracy and permits to study several characteristics of diseases (localisation, extension, disease activity, type of damage of the intestinal mucosa) and offers therapeutic possibilities too.

A complete examination can last between 20 and 45 minutes and is performed under sedation-analgesia in children.

Complications as intestinal perforation or bleeding are very rare but need to be considered with a precise preliminary assessment of the child by the paediatric gastroenterologist and by the anaesthetist; the hematologic profile and coagulation also need to be checked.

About the presence and participation of the parents until the moment of sedation and from the initial awakening of the child soon after the procedure, the same management described in the previous paragraph for upper GI tract endoscopy is also valid for colonoscopy.

A specific paragraph dedicated to bowel preparation is following.

\section{The importance of sedation-analgesia [5-8]}

The endoscopic examination of upper and lower GI tracts represents a key tool for diagnosis and treatment of several GI diseases within the paediatric population.

Even though a basic diagnostic digestive endoscopy with biopsies is not necessarily a painful procedure, it frequently represents a threatening and feared event to the child and his/her family.

The introduction of the paediatric endoscope into the bowel can be annoying and requires self-control. Moreover, the approach of the child to the setting of an Hospital can be itself a cause of severe discomfort.

The sedation-analgesia has been proved to be efficacious and safe to let the child undergo endoscopic procedures with an adequate control of pain, fear and producing an amnestic effect.

Taking care of the baby implies establishing a communication with a subject whose interactions with the outside world are consolidating and growing; at the same time, the referring adults to the baby (the parents) need also to be guided. The caring team of the child is therefore aimed to create a good level of interaction around the child and his/her family.

The strategies of communication and relationship with a child are different according to the age and require flexibility by the caring team. 
An adequate communication to the child of the principle steps of the endoscopic procedure is extremely useful to separate subconscious fantasies from reality. This is crucial to eliminate those fears or doubts of the child that may determine an inadequate cooperation during the procedure.

For these reasons, the importance of a setting to be conceived for the young patient and let $\mathrm{him} /$ her feel at ease is fundamental. The presence of an adult caring for the child (parents) is also determinant until the phase of pre-anestesia.

Even though there are no controlled randomized trials focusing on safety and efficacy, current evidences sustain Propofol as the best sedation-analgesia in the paediatric age. This drug can be safely administered by intensive care physicians even without a specialisation in anestesia, if they have an adequate experience and education thereabout.

As Upper GI endoscopy is a short lasting procedure, the baby can undergo a moderate-deep sedation with non protected airways, being placed in a comfortable position requiring the possibility of an easy access to the airways during the procedure.

During sedation-analgesia, a close monitoring of the vital parameters need to be performed (heart rate and electrocardiogram, respiratory rate, oxygen saturation, peripheral blood pressure) and the caring team needs to be necessarily trained to treat any potential emergency as well as any rare minor event or adverse effect to the drugs administered.

\begin{tabular}{|c|c|c|}
\hline Level of Sedation & Definitions & $\begin{array}{l}\text { Respiratory and Cardiovascular } \\
\text { Conditions }\end{array}$ \\
\hline Mild Sedation & $\begin{array}{l}\text { Patients normally respond to verbal orders. A } \\
\text { reduction in the cognitive functions and in the } \\
\text { coordination can be attested. }\end{array}$ & $\begin{array}{l}\text { Preserved cardiovascular and } \\
\text { respiratory functions }\end{array}$ \\
\hline Moderate Sedation & $\begin{array}{l}\text { Patients voluntary respond to verbal orders. } \\
\text { Reflexes are kept when evoked with a normal } \\
\text { response to a stimulation with pain. }\end{array}$ & $\begin{array}{l}\text { No need of interventions to keep the } \\
\text { airways patent. Adequate spontaneous } \\
\text { ventilation. Cardiovascular function } \\
\text { maintained. }\end{array}$ \\
\hline Deep Sedation & $\begin{array}{l}\text { Patients can not be easily awaken but respond to } \\
\text { pain stimulation. }\end{array}$ & $\begin{array}{l}\text { The capacity to maintain the } \\
\text { respiratory function can be } \\
\text { compromised. An assistance to keep } \\
\text { the airways open may be needed. } \\
\text { Spontaneous ventilation can be } \\
\text { inadequate and airway reflexes can be } \\
\text { completely lost. Cardiovascular } \\
\text { functions are generally maintained. }\end{array}$ \\
\hline Anestesia & $\begin{array}{l}\text { Patients cannot be awaken and do not respond to } \\
\text { pain stimulations. }\end{array}$ & $\begin{array}{l}\text { Patients require an assisted ventilation, } \\
\text { since their cardiovascular functions can } \\
\text { be compromised. }\end{array}$ \\
\hline
\end{tabular}

Table 1. Definition of the Levels of sedation (American Academy of Paediatrics, modified) [8] 
Operative endoscopies or endoscopies performed on patients at risk for severe surgical complications need to be performed with protected airways and in the adequate setting of the surgery room.

\section{Bowel preparation [9]}

The majority of the paediatric bowel preparations available,is derived from the products existing for the adults. The process of bowel preparation in the paediatric population is age dependent, considering that the older is the child the more he collaborates.

The poor palatability of most of preparations and the need to ingest large amounts of liquid volumes, are two main limitations for the compliance of the paediatric patient.

As a consequence, it is often difficult in children to reach an adequate level of bowel cleaning.

Children do not easily tolerate the bowel preparations schedules, mainly because of the appearance of vomits, nausea and abdominal distension.

The use of an 8 French nasogastric tube is therefore often required to administer the preparation and this last procedure necessarily requires hospitalisation.

An at-home preparation would be instead ideal for paediatric patients, within a more comfortable and familial environment. A careful evaluation of the familial compliance is by the way to be firstly attested.

Since endoscopic procedures in the child require sedation, a fasting period has to be set before the examination.

The whole process of preparation can be significantly improved by an adequate involvement of parents (who are affectively closed to the child), letting one of them staying next to the child until the pre-sedation phase. A "child oriented" Endoscopic Room is also of great help to improve the child feelings and compliance.

There are currently no ideal preparations. The optimal theoretical characteristics of a bowel preparation would be safety, efficacy, tolerability and absence of contraindications.

\section{Why is bowel cleaning important?}

- Higher probability of reaching the cecum and terminal ileum through the Bauhin valve;

- A clearer and more complete vision is obtained, with an easier detection of possible lesions;

- Safety and efficacy of the examination are improved;

- An inadequate bowel cleaning relates to an increased risk of complications (i.e. bowel perforations); moreover the presence of faeces increases the infective risk during the operative procedures. 


\section{Basic instructions for bowel preparation}

During the seven days preceding the endoscopic examination, a diet poor in fibers and rich in liquids should be suggested.

The day before the procedure a light breakfast (i.e. tea, milk, white bread slices with marmalade, dried biscuits, yoghurt) is indicated.

According to the scheduled timing of the endoscopic exam the day after, a light brunch can be prepared with half-liquid sugared products. The time of fasting is then programmed and the administration of the bowel preparation is then initiated. Faeces have to be viewed.

Until 3 hours before the examination, clear liquids i.e. tea and water can be introduced.

Six hours before the examination, the administration of the bowel preparation has to be interrupted.

For small infants, an adequate bowel cleaning can be obtained with enemas using small volumes of physiologic solution $[20 \mathrm{ml} / \mathrm{Kg}$ ) and substituting milk-feeding (breast, formulas) with clear liquids about 12-24 hours before the procedure.

Pharmacological Products: Stimulating Laxatives, Osmotic Laxatives, Solutions for Bowel Washing (Irrigation)

- Stimulating Laxatives: Bisacodyl, Senna, Sodium Picosulfate [10]

Elevated doses are required to obtain an efficacious cleaning. These products are converted by intestinal flora into active metabolites influencing the colonic motility by an acceleration of intestinal transit time. The absorption of liquids is reduced and the processes of secretion are modified.

Side effects include spastic abdominal pain, nausea and vomit.

This class of preparations is not currently indicated for the paediatric age.

- Osmotic Laxatives [11]

They represent the most indicated subclass of preparations for the paediatric age and include Lactulose, Magnesium Citrate, Polyethylene Glycol, Sodium Phosphate.

Lactulose,Mannitol and Sorbitol are sugars which are poorly absorbed by the intestinal mucosa.

They attract water within the intestinal lumen by an osmotic effect.

Side effects include:

- Significant loss of liquids and electrolytes;

- Bacterial fermentation of the non absorbed sugar with increase in the risk of infections

- Magnesium Salts are poorly tolerated and the bowel cleaning is therefore often inadequate. They are uneasily used within the paediatric population; 
Sodium Phosphate is not to be used in children with chronic diarrhoea or body weight loss, intestinal obstruction, paralytic ileum, diseases of heart, kidney and liver [10-12].

It can cause aspecific erosions and ulcers on the colonic mucosa and can thus falsify the yield of the endoscopic examination, mimicking the typical lesions of IBD.

Others side effects involving mainly children and elderly people include severe electrolite alterations (hyperphosphatemia, hypocalcemia, hypokalemia), dehydration and renal failure.

It is generally orally administered with hypertonic solution, resulting palatable and efficacious for adult patients. A good safety has been also demonstrated within the adult population whereas it should be used with caution in children.

Patients willingly accept it because it requires a minor quantity of liquids with respect to other preparations.

The Food and Drug Administration of the US and Health Canada, have approved the following recommendations in terms of bowel preparation:

- The use of oral Sodium Phosphate is not recommended, whatever its indication might be, in children aging $<5$ years;

- The use of oral Sodium Phosphate is not recommended for bowel preparation in children aging < 18 years;

- The use of oral Sodium Phosphate can be used in patients aging 6-18 years in case of occasional constipation only;

- The patient has to introduce a large amounts of liquids before and after bowel preparation.

PEG (Polyethylen Glycol) is a polymer with molecular weight of 3500-4000 Daltons, and cannot be absorbed by the intestinal mucosa [11].

The PEG based electrolytic solutions available have to be osmotically balanced.

The use of PEG does not determine any passage of water nor electrolytes from or towards the bowel. PEG does not undergo bacterial fermentation. Several clinical trials demonstrate its efficacy. Its palatability is however limited. The ingestion of large amounts of liquids (at least 1-2 L) is required when PEG is used.

Possible gastrointestinal side effects include nausea, vomit, abdominal distension and pain.

\section{Useful strategies to help bowel preparation with PEG include [13]:}

- Administration of prokinetic drugs (i.e. Metoclopramide, Domperidone);

- Utilization of a nasogastric-tube (8 French) is suggested in children aging $<3$ years or to prevent the risk of inhaling and ab-ingestis pneumonia, particularly in those patients with altered swallowing reflex or compromised mental state. A volumetric pump may also be used; 
- Suggested dosage for the paediatric patient: $30-40 \mathrm{ml} / \mathrm{Kg} / \mathrm{h}$

PEG is not recommended in case of [13-14]:

- Founded suspect of luminal lesions obstructing the bowel;

- Severe abdominal pain;

- Vomits;

- Acute severe colitis (a bowel preparation can increase the risk of perforation and progression to Toxic Megacolon)

\section{Peculiar situations in bowel preparation}

- Patient with diarrhoea: lower amount of preparation is indicated;

- Patient with chronic constipation: larger amount of preparation is indicated; pre-procedural enemas can be considered;

- Patient with gastrointestinal bleeding: lower amount of preparation is indicated (blood has a prokinetic effect);

- Patient with partial intestinal obstruction: larger amount of preparation is indicated and enemas of isotonic saline solution to be effectuated two hours before the procedure.

\section{Endoscopy and main clinical settings in paediatrics}

\subsection{Gastroesophageal Reflux Disease (GERD) [15-17]}

Upper digestive endoscopy represents the gold standard for detection of pathologic GER complications; a high specificity is obtainable thank to the histological analysis of the bioptic specimens.

The Savary Classification defines 4 grades of esophagitis:

1. Mucosal exudation

2. Non confluent erosions

3. Confluent erosions

4. Ulcers. Fibrosis, stenosis and/or brachi-oesophagus

5. Barrett oesophagus

Another Classification for esopghaitis is the Los Angeles Classification [18] which identifies the following 4 grades:

- Grade A: One (or more) mucosal break no longer than $5 \mathrm{~mm}$, that does not extend between the tops of two mucosal folds (a mucosal break being defined as an area of slough or erythema with discrete demarcation from the adjacent mucosa); 
- Grade B: One (or more) mucosal break more than $5 \mathrm{~mm}$ long that does not extend between the tops of two mucosal folds;

- Grade C: One (or more) mucosal break that is continuous between the tops of two or more mucosal folds but which involves less than $75 \%$ of the circumference;

- Grade D: One (or more) mucosal break which involves at least 75\% of the esophageal circumference.

Barrett oesophagus can itself be subclassified within three types:

1. Defined border between oesophageal and gastric epithelia (more typical of the child);

2. Portions of oesophageal squamous epithelium are within the context of the gastric cylindrical epithelium

3. Cylindrical metaplasia with no circumferential distribution, but with stretches of tissue departing from the $\mathrm{Z}$ line.

Oesophageal erosions are lesions covered by fibrin and with erythematosus borders; they are confined within the tonaca mucosa and do not reach the submucosa.

Oesophageal ulcers can differently involve the deeper levels causing hemorrhagic phenomena which can be endoscopically treated.

In children with peptic esophagitis, the lower part of the oesophagus is generally involved whereas the upper tracts are mainly macroscopically normal.

Typical histological patterns in peptic esophagitis include eosinophilic infiltration (>2 eosinophils/HPF), neutrophilic infiltration ( $>2$ neutrophils/HPF), basal zone hyperplasia ( $>$ $20 \%$ ) and papillary hyperplasia.

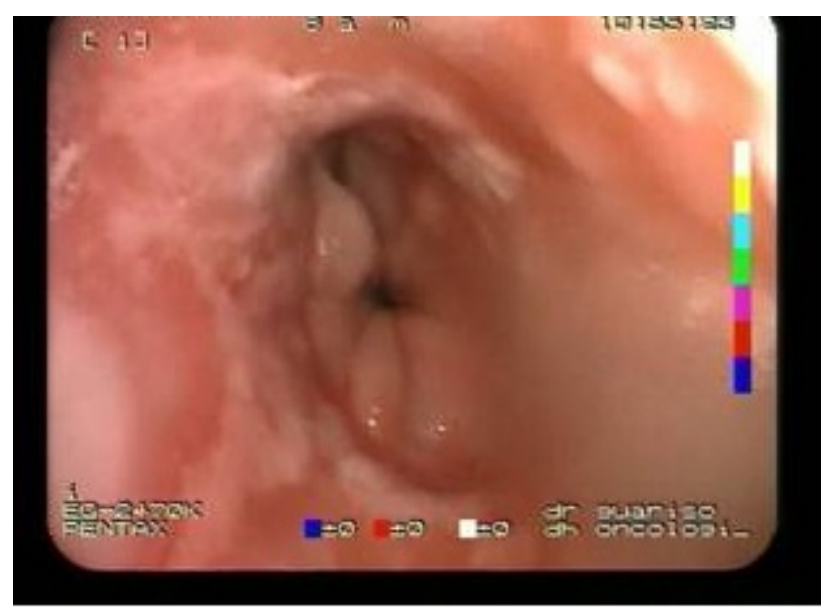

Figure 1. Peptic esophagitis (Grade 3) 
The Boyle Classification associates the endoscopic and histological patterns:

- Grade 1: Extension of the papilla, increased thickening of the lamina propria; presence of eosinophils or neutrophils (1-19 cells/HPF);

- Grade 2: Same patterns as Grade 1, but with a higher number of neutrophils or eosinophils (> 20 cells/HPF);

- Grade 3: Endoscopically or histologically defined erosions (Fig. 1);

- Grade 4: Endoscopically or histologically defined ulcerations;

- Grade 5: Oesophageal stenosis or Barrett oesophagus.

\subsection{Eosinophilic esophagitis [16-17-20]}

Eosinophilic Esophagitis (EE) is an important disorder due to an Inflammatory condition of the esophagus that is characterized by having above normal amounts of eosinophils.

The symptoms of EE may vary with age. The clinical presentation of EE may be confused with GERD especially in younger children. Infants often present with vomiting, irritability and poor weight gain. In the older child and adolescent, difficult swallowing and food obstruction or impaction in the esophagus may be more common.

Other symptoms might include reflux not responsive to standard medical therapy, nausea, vomiting, abdominal or chest pain, poor appetite, and sleeping difficulties.

An upper endoscopy with biopsies is necessary for diagnosis of EE. The appearance of the esophagus in EE is quite characteristic (Fig. 2): a wrinkled or furrowed and ringed esophagus is covered with whitish material or exudate.

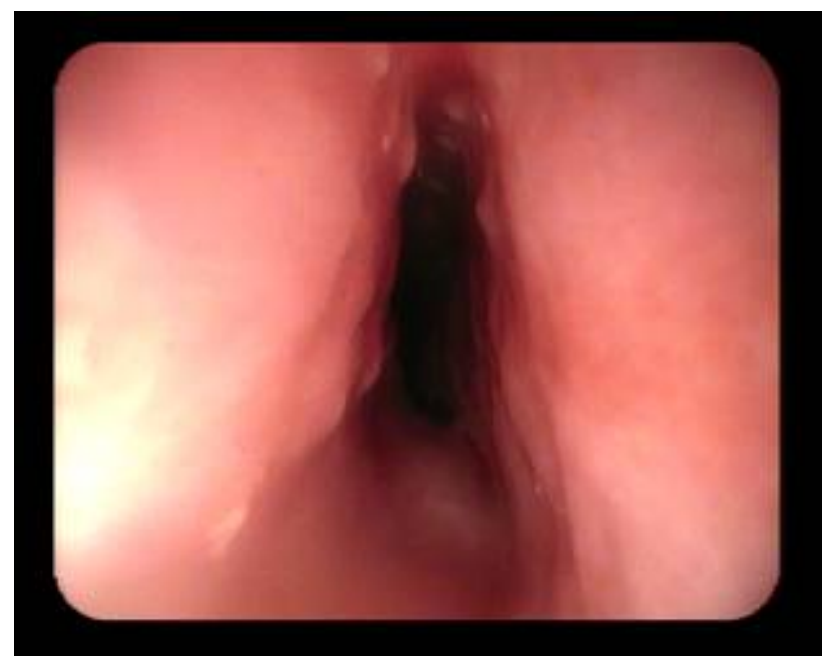

Figure 2. Eosinophilic oesophagitis 
However, the esophagus may look normal.

The diagnosis of eosinophilic esophagitis is set on the histological evidence of $>15$ eosinophils/HPF (normal values $<3$ ). No eosinophils are detected at gastric and duodenal biopsies.

Elevated peripheral blood levels of eosinophils as well as of total IgE are also observed.

Patients' symptoms increase to normality after a 4 week treatment with prednisone. A dietary restriction is also efficacious for these patients.

\subsection{Candida associated and immunodeficiency associated esophagitis [18]}

Candida associated esophagitis can be found both in immunodeficient patients (i.e. HIV affected patients, Fig. 3 and 4) as well as in basically healthy subjects. The mid oesophagus is generally the mainly involved tract. A variable endoscopic pattern can be found: the mucosa mostly appears crispy and erythematosus, and can be accompanied by plaques, erosions, ulcerations and nodularities. Lesions are mostly covered by whitish exudation.

Oesophageal candidosis can be found also in the absence of an oral localisation.

The distal oesophageal tract is often spared because of the acidic reflux protection.

Patients with immunodeficiencies (i.e. lymphoma, leukemias) can also present herpetic oesophageal lesions determining a mucosal pattern similar to the one of Candida infection, thus the histological examination is needed for the differential diagnosis. Several systemic immuno-mediated diseases can be associated with gastrointestinal involvement, also in the absence of infections [19].

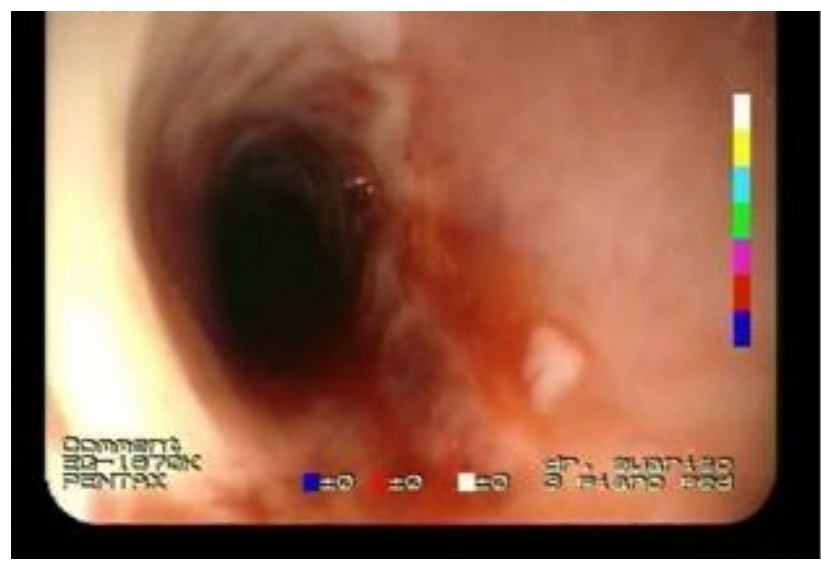

Figure 3. CMV related esophagitis in an immunodeficient patient 


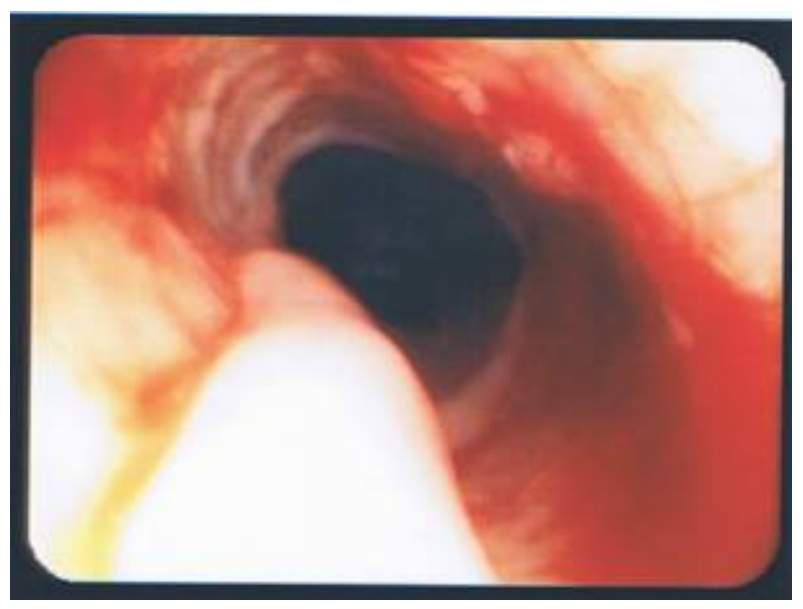

Figure 4. Oesophageal mycetomas in a child with AIDS

\subsection{Oesophageal neoplasia [18]}

Primitive oesophageal neoplasias are rare in the paediatric age. The most frequent type is oesophageal leiomyoma which is generally found during adolescence.

In the paediatric age all oesophageal parietal layers are infiltrated and the whole oesophageal length is involved in $30-40 \%$ of cases.

Children are often symptomatic presenting disphagia, weight loss, hematemesis, cought, dyspnea, retro-sternal pain and vomit.

A lesion protruding into the oesophageal lumen is endoscopically detected, without alterations of the oesophageal mucosa.

Differential diagnoses include mediastinal masses or achalasia.

Surgical resections represent the available treatments (tumor enucleation, oesophagectomy, oesophagus-gastrectomy).

Oesophageal adenocarcinoma and metastases are extremely rarely detected in adolescence.

\subsection{Oesophageal varices [21]}

Variceal bleeding as a consequence of portal hypertension is one of the complications of paediatric chronic liver diseases.

Portal hypertension is defined as portal vein pressure $>5 \mathrm{mmHg}$ or a portal vein to hepatic vein gradient of $>10 \mathrm{mmHg}$.

The level of portal vein obstruction can be pre-sinusoidal (intra or extra-hepatic), sinusoidal or post-sinusoidal. 
Extrahepatic portal vein obstruction is the most frequent cause of paediatric portal vein hypertension, and is mainly secondary to instrumentation of the umbilical veins in neonates, congenital malformation, omphalitis or intra-abdominal infections.

Intrahepatic presinusoidal portal hypertension is observed in congenital hepatic fibrosis and schistosomiasis.

Among the causes of post-sinusoidal portal hypertension are Budd-Chiari Syndrome, webs in the supra-hepatic vena cava, veno-occlusive disease and cardiac disease.

The management of the three levels of portal obstruction relates to the evidence that liver function is almost always normal in extra-hepatic and pre-sinusoidal obstructions whereas it is generally impaired in sinusoidal or post-sinusoidal obstructions.

Ascites is generally only present when portal hypertension is at the sinusoidal level.

Four main portal to systemic vein collateral systems become prominent in portal hypertension: the paraumbelical venous network (caput medusa), the perirectal collateral venous system, gastric varices and oesophageal varices which are best examined by endoscopy.

Once portal hypertension is suspected on clinical and US findings, elective upper endoscopy can give useful information about the size, localisation and grade of the varices.

Variceal bleeding is the most serious complication of portal hypertension, with a $30-50 \%$ mortality and high risk of rebleeding. The main factors predicting variceal bleeding are portal vein-hepatic vein gradient $>12 \mathrm{mmHg}$; large, tense varices; red wale marks, red spots on varices; severity of underlying liver disease.

In children, the risk of bleeding may change over time; in those with extra-hepatic portal vein obstruction, the development of a decompressive collateral circulation may decrease the risk with age.

Hematemesis or melena as a result of variceal bleeding is often massive, and children may present a cardiovascular shock. In these cases, resuscitation efforts and intravenous vasoconstrictor therapy are begun. Clotting factor supplementation should also be instituted immediately.

Upper-GI endoscopy is required primarily to confirm the site and cause of bleeding and to determine if treatment is indicated. A differential diagnosis of other etiologies of upper-GI bleeding includes portal hypertensive gastropathy, gastric and duodenal ulcers and Mallory-Weiss.

In most Centres, oesophageal varices are graded according to their size:

Grade 1: Small straight varices;

Grade 2: Medium enlarged tortuous varices occupying less than one third of the lumen;

Grade 3: Large coil-shaped varices occupying more than one thirs of the lumen.

A recent consensus from the American Association for the Study of Liver Diseases (AASLD) recommends to use 2 grades (small and large) with a cut-off size of $5 \mathrm{~mm}$. 
The North Italian endoscopic club for the study and treatment of esophageal varices indicates a classification based on variceal size (small, medium, large), severity of red wale marks (absent, mild, moderate, severe) and Child-Pugh class (A-C). A risk stratification for variceal bleeding accompanies this classification, with cumulative scores for individual features added to define a risk class.

If esophageal variceal bleeding is confirmed, therapeutic sclerotherapy or variceal ligation is indicated.

Sedation, intubation and balloon tamponade may be the only method to stabilize a patient with persistent uncontrolled bleeding: this represents by the way only a temporizing measure, since balloons can be safety left inflated for 12-24 hours.

Prevention of rebleeding and prophylaxis of first variceal bleeding include sclerotherapy, variceal ligation, vasoactive drugs and portosystemic shunts.

Sclerotherapy is the first well-established modality to control variceal bleeding in children, and has decreased the need for shunt surgery. It is now increasingly being replaced by band ligation, which appear to be safer and more effective. Both techniques usually require repetitions in order to successfully eradicate oesophageal varices in up to $90 \%$ of patients.

By the way, until the child undergoes a definitive procedure that decreases or eliminates portal hypertension (i.e. shunt operation or liver transplant), a risk of life-threatening variceal bleeding remains, often from newly formed gastric varices

Portal hypertensive gastropathy with increased bleeding risk may also be exacerbated by esophageal variceal obliteration. Gastric varices are not amenable to either sclerotherapy or ligation.

\subsection{Gastritis [22-24]}

\section{Acute Gastritis}

Acute gastritis can be secondary to infections (i.e. virus, Helicobacter Pylori (Fig. 5), Salmonella), drugs (i.e. NSAID, cortisone, chemotherapy), uremia (i.e. acute and chronic kidney failure), stress (i.e. surgical intervenctions, burns), shock. In adolescents mainly smoking, alcohol and drugs' assumption can relate to this kind of disease.

Three endoscopic degrees of acute gastritis are described:

- A mild form with mucosal oedema and hyperaemia;

- An intermediate form with haemorrhagic lesions (Fig. 6];

- A severe ulcerative form with extended deep erosions.

The histological pattern is characterised by leucocitary inflammation with a more frequent antral localisation 


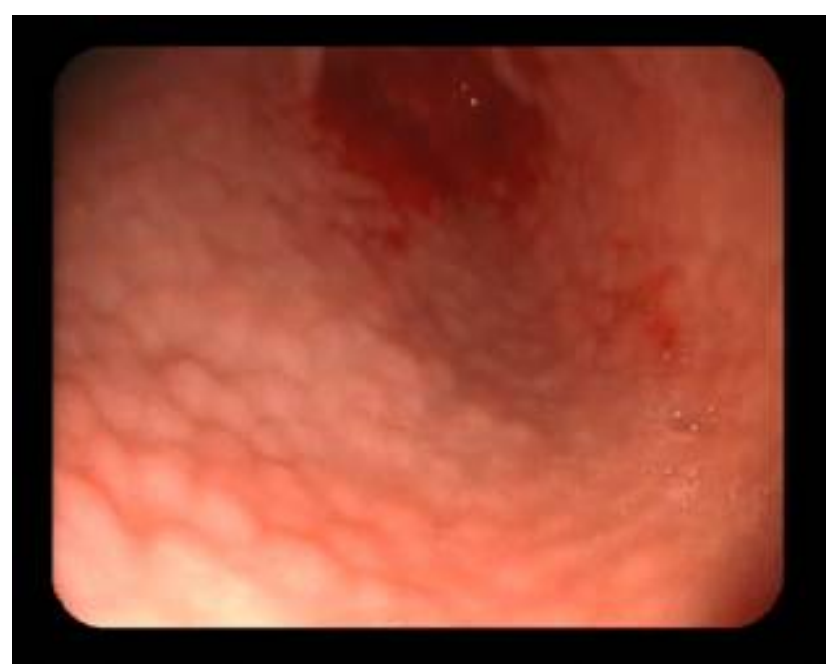

Figure 5. Helicobacter Pylori gastritis

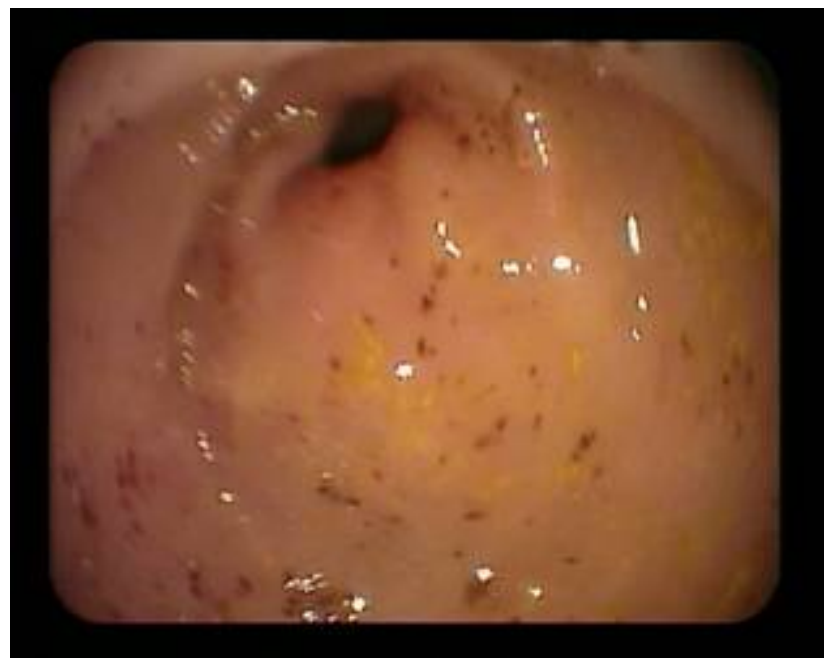

Figure 6. Haemorragic gastritis

\section{Chronic Gastritis}

Chronic gastritis represents a frequent finding in the paediatric age, and is endoscopically characterized by gastric atrophy (Fig. 7). The histological pattern shows an increased mucosal inflammatory infiltration as well as a glandular atrophy, with different degrees of severity (superficial, atrophic and gastric atrophy). Localisations at the gastric antrum, body and fun- 
dus can be detected. As regards the antral localisation, HP has a main epidemiologic role. An HP related pangastritis can also be observed. The localisation at fundus is mainly of auto-immune nature.

Atrophic gastritis can be associated to gastric metaplasia or displasia, even though this remain exceptional in the paediatric age.

Chronic gastritis can be classified as active (polimorphonucleate and eosinophilic infiltration) or quiescent (lymphocitic cell infilatration). The endoscopical pattern is characterized by hyperhaemic areas with edema and exudative secretions, alternated with opaque areas, creating a mucosal jeopardized aspect. Ulcers can also be evidenced within the inflamed areas of the mucosa.

A superficial erosive gastropathy is endoscopically characterized by minimal spotted loss of substance and whitish exudative areas with heritematosus profile.

HP related gastritis has an endoscopic pattern characterized by nodular intensively inflamed mucosal areas. Erosions and fibrine can also be found on the inflamed areas.

HP colonises the interface between gastric epithelium and mucus, and can be easily detected on gastric biopsies through specific stainings.

$\mathrm{HP}$ gastritis is a risk factor for development of gastric cancer in adults as well as for gastric lymphoma in children.

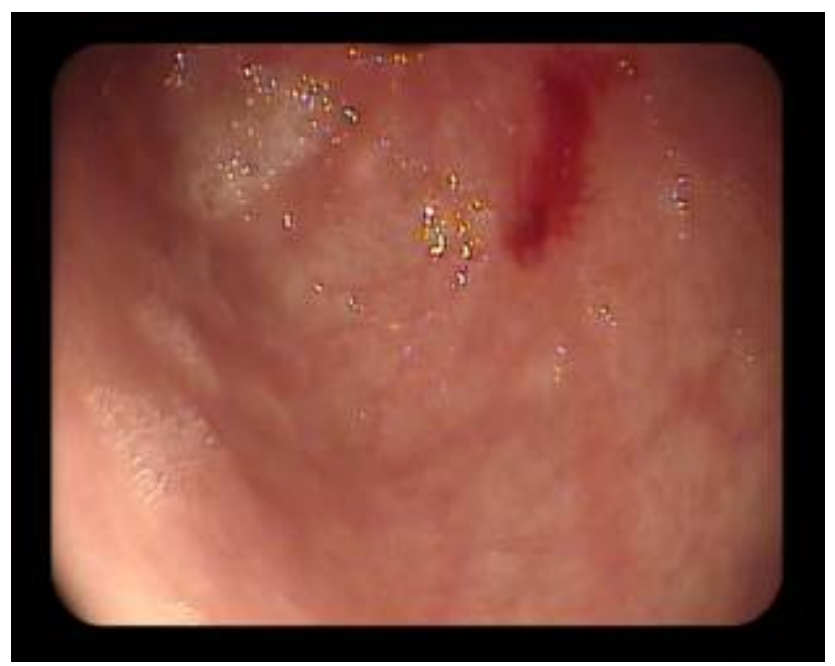

Figure 7. Atrophic gastritis

Even though peptic ulcers are rare in the paediatric age, their prevalence among children and adolescents with HP gastritis is much higher with respect to those patients without HP infection. 
Haemorrhagic gastropaties are mainly secondary to stress, NSAIDs assumption or infections; the endoscopic pattern is characterised by hyperhaemic bleeding areas, sometimes with petechiae.

\subsection{Gastric ulcers [22-24]}

Gastric ulcers are discontinuities of the gastric mucosa with penetration to the muscolaris mucosae and exposure of the submucosa.

The Forrest Classification describes three types of peptic ulcers, basing on the characteristics of the associated upper gastrointestinal haemorrhage [25]:

Forrest Ia: Spurting arterial bleeding (Fig. 8);

Forrest Ib: Oozing arterial haemorrhage;

Forrest IIa: Large non-bleeding visible vessels (Fig. 9);

Forrest IIb: Adherent clot;

Forrest IIc: Haematin on ulcer base;

Forrest III: Lesions without signs of recent haemorrhage.

Primitive ulcers are caused by alterations of the gastric function $(\mathrm{HCl}$ production and pepsin function); they are mainly single lesions and are usually found at the small gastric curve and at the antrum.

Secondary ulcers are instead caused by extra-gastric pathogenic events, i.e. stress or drugs. They can be multiple and can have a spread localisation within the stomach.

$\mathrm{HP}$ is often involved in the pathogenesis of gastric peptic ulcers. Neoplastic ulcers are instead related to development of lymphoma.

Benign ulcers are endoscopically characterized by mild dimensions, oval or roundish shape, and by a whitish-grey base, consisting in covering fibrin and granulation tissue. Borders are thin and plane. A basal vase can be detected and represent a source of haemorrhage. Gastric plicae are usually converging to the ulcer.

Malignant ulcers generally present an irregular base, with necrotic base covered by fibrin. However, only the histological examination can differentiate the two ulcer types.

Drug-associated ulcers are mainly associated to treatments with NSAID, steroids, anti-neoplastic drugs, immunosuppressive drugs. A reduction of the protective effect of prostaglandins on gastric mucosa is considered to be the main pathogenetic mechanism.

Other stressful events (i.e. shock, sepsis, burnings, major trauma, endocranial hypertension, surgical procedures, chronic diseases) can cause acute gastric ulcers, also in the paediatric age. Lesions generally appear 3-6 days after the event and the main related symptoms are bleeding and abdominal pain. Most of times they are multiple lesions involving any part of the stomach. Intracranial illness related gastric lesions are called Cusching ulcers, whereas 
burning related lesions are named Curling ulcers. The endoscopic pattern is characterized by mucosal oedema, bleeding and focal erosions.

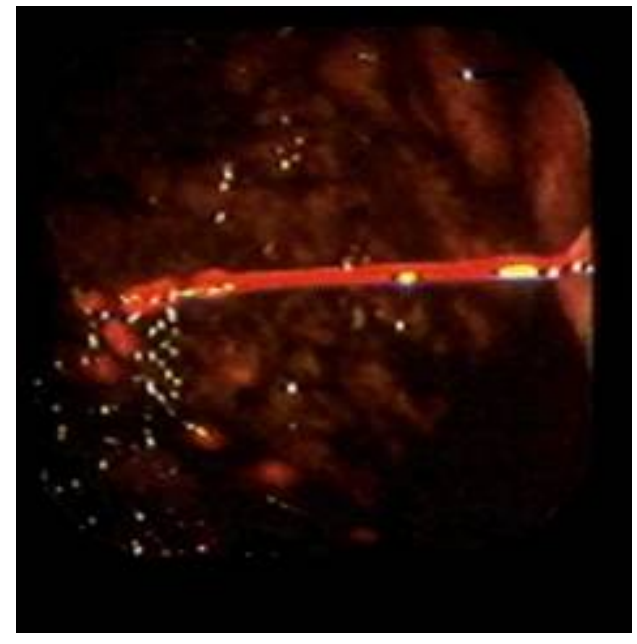

Figure 8. Peptic Ulcer (Forrest 1A)

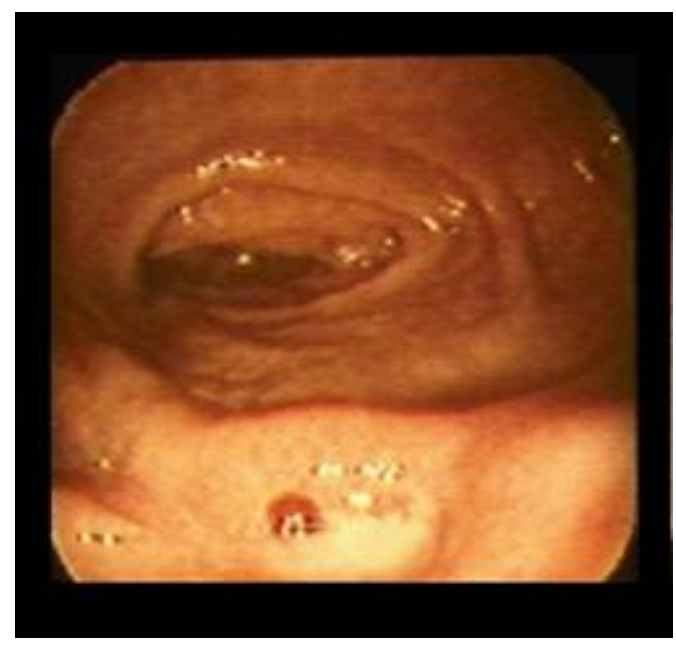

Figure 9. Peptic Ulcer (Forrest 2A) 


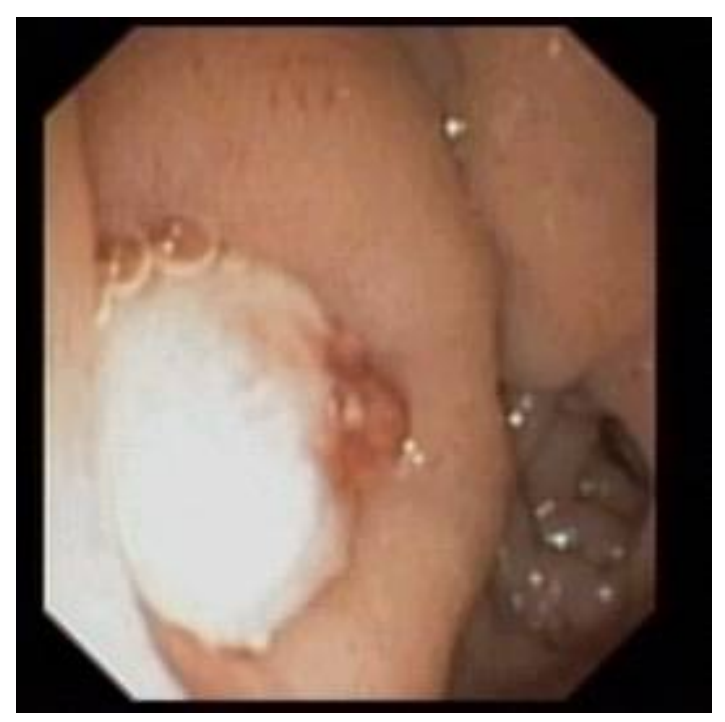

Figure 10. Bleeding bulbar ulcer

\subsection{Granulomatous gastritis [22]}

Several different illnesses (including Crohn's Disease) can cause granulomatous gastritis. Gastric involvement can be isolated or in association with other gastrointestinal tracts. Lesions can be found at multiple gastric localisation and can present as erythematosus-nodular gastropathy, aphthous lesions, deep linear or serpiginous ulcers. Antral pseudopolyps conferring a cobblestone pattern to the mucosa can be observed. Pyloric obstructions can be evidenced in Sarcoidosis; in those cases a nodular mucosa with thickened rigid gastric plicae can be observed, simulating the pattern of infiltrating lymphoma.

Tubercular gastritis also represents a rare but possible infection, which can be secondary to miliar diffusion of the disease as well as related to a primitive infection by mycobacterium bovis or atypical mycobacteria in immunocompromised subjects.

Mycotic infections in immunocompromised patients (including Histoplasma, Phicomyceti, Candida, Aspergillus), can also cause granulomatous gastritis, mainly when disseminated at multiple organs.

\subsection{Eosinophilic gastritis [22]}

This rare disease is characterised by peripheral blood hypereosinophilia, accompanied by an eosinophilic infiltration of the whole gastro-intestinal tract involving at least mucosa and submucosa. Gastric mucosa assumes a thickened nodular pattern, with bulging gastric plicae and partial obstruction of the antral-pyloric lumen. Eosinophilic granuloma appearing 
as polypoid lesions can be observed, as well as erosive phenomena. An involvement of duodenum can also be often attested.

Familiarity for allergies is frequently evidenced.

The disease symptoms include abdominal pain, vomit, iron-deficient anaemia, melena and protein loosing enteropathy. The involvement of the muscular tunica can cause dysmotility and sub-occlusive phenomena. The infiltration of serosa can induce formation of ascites.

\subsection{Hyperplastic plical gastropathy [22]}

Three variants of this disease are described: Ménétrier disease is caused by hyperplasia of superficial mucosal cells with gastric hyposecretion; Hypertrophic Hypersecretive Gastritis; Zollinger-Ellison syndrome, which is related to active gastrinoma within multiple endocrinological affections (MEN 1].

The paediatric variant of Ménétrier disease has peculiar characteristics with respect to the variant of the adult: the paediatric disease is generally CMV associated, and allergic and immune-mediated phenomena are considered to have a pathogenetic role in the disease development. The disease is generally self-limiting and with favourable prognosis in children.

Related symptoms are anorexia, body weight loss and protein loosing enteropathy.

The endoscopic pattern is characterised by giant hypertrophic plicae, conferring to the mucosa a cerebral-like pattern and without any efficacious distension with endoscopic air insufflation.

Zollinger Ellison is endoscopically characterised by multiple and persistent gastric and duodenal ulcers. A hypertrophy of the gastric plicae is observed as secondary to hypergastrinemia. Disease diagnosis requires detection of elevated blood levels of gastrine in basal condition as well as after stimulation with proteic meals or with secretine.

\subsection{Gastric vascular anomalies [22]}

They can be classified as non-neoplastic forms (comprehending congestive gastropathy secondary to portal hypertension, varices, teleangectasies and angiodysplasias) and neoplastic forms (angiomas, angiosarcomas and Kaposi sarcoma).

Portal hypertension can be secondary to pre-hepatic causes (i.e. portal vein cavernoma), hepatic causes (biliary cirrhosis) and post-hepatic causes (Budd-Chiari Syndrome).

The endoscopic pattern is characterised by a darker reddish colour of gastric mucosa, which appears more evident at the antrum and gastric body, with petechiae, haemorrhagic spots or with more diffuse hemorrhagic lesions (Fig. 11]. Varices of the gastric fundus can be often associated.

Gastric varices typically surround the cardial-oesophageal junction, developing in the submucosa and determining an endoscopic pattern of curved protrusions. The blue colour which is typically seen in oesophageal varices, is not generally attested in gastric varices 
(due to different mucosal thickening), so that they can be easily misrecognised as hypertrophic gastric plicae.

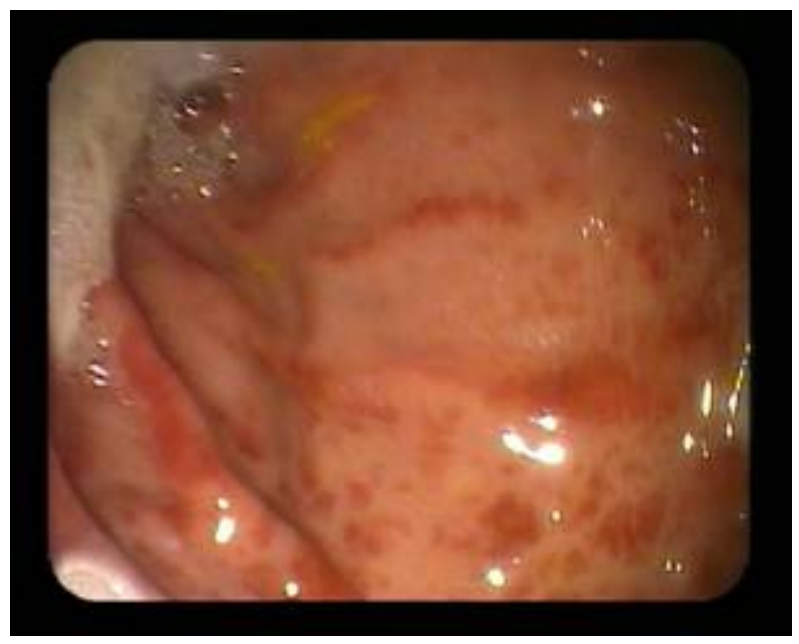

Figure 11. Congestive gastropathy

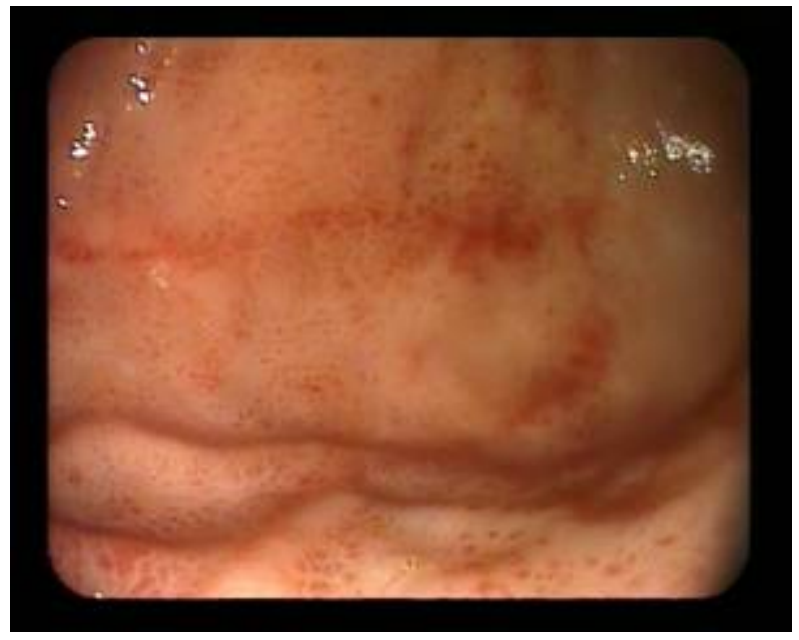

Figure 12. Gastric GVHD in a child with BMT

\subsection{Graft versus Host Disease (GVHD) after Bone Marrow Transplantation (BMT)}

The stomach is among the several organs which can be involved in GVHD syndrome. 
The main clinical features are anorexia, nausea, vomit, watery diarrhoea, abdominal pain, gastrointestinal bleeding and body weight loss [21].

Endoscopic features include oedema, erythema, erosions, ulcerations and mucosal bleeding (Fig. 12); every portion of the stomach can be potentially involved.

The histological pattern is characterised by apoptosis of the cryptic epithelial cells, exploding crypts, lymphocytic infiltration of epithelium and lamina propria.

Rectal-sigmoid biopsies are more accurate for diagnosis of GVHD in comparison to samples from the upper GI tract $(p<0.0001)$.

\subsection{Ingestion of Caustic Substances [26-27]}

In the paediatric age, caustic ingestion is still among the indications to endoscopy, which represents the most appropriate technique to evaluate mucosal lesions at the level of oesophagus and stomach.

House products are nowadays less involved in causing severe lesions thank to safer packaging and to reduced concentration of active caustic substances. On the other hand, professional and industrial caustic products still represent a concrete risk for children.

Mucosal damages determined by caustic ingestion, depend on the $\mathrm{pH}$ and concentration of the ingested substance.

Alcaline substances (sodium hydroxide, ammonium, sodium hypochlorite) with a concentration superior to $20 \%$ cause colliquative necrosis with deep lesions which can determine visceral perforations. When lesions involve muscular oesophageal layers in their whole circumference, stenoses and shortening of the oesophagus can be generated (Fig. 13).

Acid substances can provoke airway damages, whereas at the level of oesophagus coagulative necrosis reduces the penetration into parietal layers as well as the risk of stenoses (Fig. 14).

In the stomach, alcaline substances are neutralised by gastric acidity, but the generated exothermic reaction can cause burning lesions, mainly at the antral and pyloric regions. An accurate anamnesis is of fundamental importance to detect the nature of the ingested substance. Symptoms generally include vomit, breathing difficulty, hematemesis, excessive salivation.

The presence of lesions at the oral cavity and at hypopharynx does not relate to the severity of the oesophageal and gastric lesions.

Endoscopy represents the main diagnostic technique to evaluate the presence, severity and extension of lesions.

Before endoscopic examination, patients need to present stable general conditions and vital parameters, through correction of shock status and intubation. A chest x-ray should be performed to exclude pneumomediastinum and pneumoperitoneum which are mainly observed in adults who ingest caustics with suicidal aim. 
A 12 hour time interval since ingestion, is recommended to estimate the real entity of extension and depth of caustic lesions. After $48 \mathrm{~h}$ since ingestion, however, the parietal colliquation can render the mucosa fragile and an excessive air inflation can cause perforations.

During the endoscopic evaluation of the oesophagus, air inflation has to be minimized. The most severe damages are generally found at the superior and intermediate oesophagus.

Caustic esophagitis is generally classified within three degrees of severity:

- $1^{\text {st }}$ degree: Diffuse mucosal hyperhaemia, spotted areas of dysepithelisation without fibrin deposits;

- $2^{\text {nd }}$ degree: Hyperhaemic mucosa with deep dysepithelisation and withish pseudomembranes which are typically linear and do not converge;

- $3^{\text {rd }}$ degree: The whitish pseudomembranes converge and involve the entire oesophageal circumference for a variable extension from a few centimetres to the whole oesophagus;

These lesions are rare findings in the paediatric age, whereas they are more common in adults who ingest caustic substances with suicidal intents. They are severe necrotic dark lesions extended to the whole oesophageal mucosa. The surgical resection of the oesophagus can be indicated to prevent perforation and mediastinitis. In the stomach, the most active damage is localised at the body, big curve, antrum and pylorus. Duodenal lesions are generally rare.

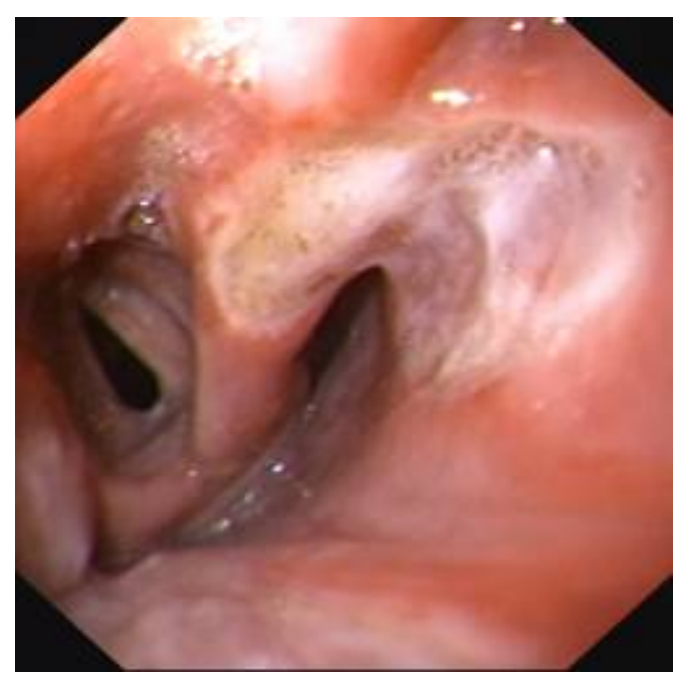

Figure 13. Caustic esophagitis 


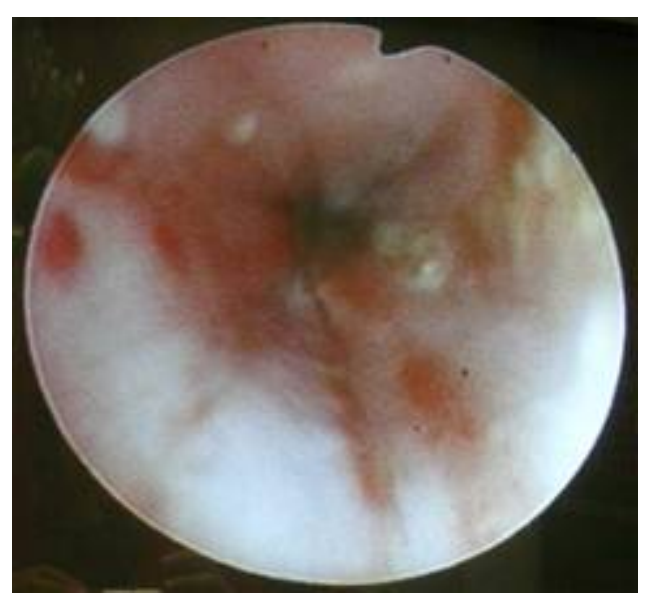

Figure 14. Esophagitis secondary to Chlore ingestion

\subsection{Coeliac Disease [28]}

Coeliac Disease represents one of the most common duodenal diseases in the paediatric-juvenile age.

A gluten-induced intolerance determines mucosal damage of the duodenum in genetically predisposed subjects.

Typical and atypical symptoms include malabsorption (diarrhea, body weight loss, growth deficit, dystrophia), anemia, hepatic affection, osteopoenia, neurological alteration, dental enamel dysplasia.

The diagnosis is based on the histological examination of the duodenal mucosa at the second duodenal portion. The endoscopic duodenal pattern is characterised by pale nodular mucosa, with vanishing and "scalopping" plicae.

The histological pattern evidences villous atrophy with decrease alteration of villous/cryptal ratio, and lymphocytic infiltration.

For the paediatric age, the new Guidelines of the European Society for Paediatric Gastroenterology, Hepatology, and Nutrition (ESPGHAN) state that in those cases with clear symptoms and a level of Anti Transglutaminase Antibodies IgA above 10 times the upper normal limit, a diagnosis can be set without the need of intestinal biopsy (Positivity for EMA and HLA DQ2 and/or DQ8 is also required).

\subsection{Infective Colitis [29]}

Infective colitis are common events at all ages, but most frequently in children aging less than 5 years. 


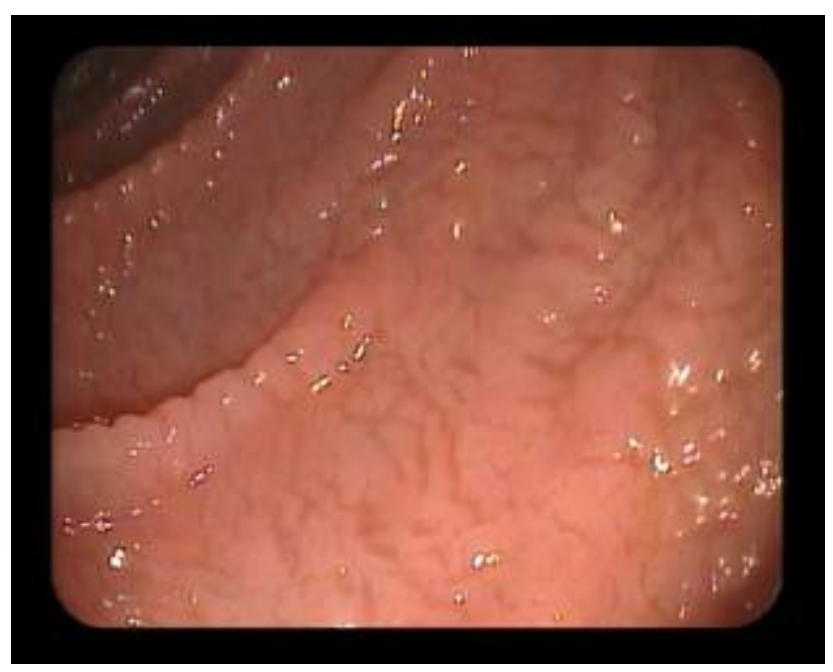

Figure 15. Scalopping of duodenal plicae in Coeliac Disease

The diagnostic ascertainments include clinical, hematochemical and cultural investigations.

Lower-GI endoscopy can have a role in the differential diagnosis, since the endoscopic pattern of infective colitis can be misrecognised as an inflammatory bowel disease, therefore the histological examination is determinant for a final diagnosis.

In the paediatric age, minor Salmonella can determine localisations at the level of the small bowel as well of the colon and rectum. The mucosa presents oedema, hyperhaemia, and in the most severe forms ulcers and bleeding or necrotic plaques.

Other bacterial infections include E. Coli, Yersinia, Campylobacter, Vibrions and Shigella.

Pseudomembranous colitis caused by Clostridium Difficile can affect paediatric patients treated with prolonged or recurrent antibiotic therapies for chronic affections.

Symptoms include bloody diarrhoea and progressive decrease in general conditions.

The endoscopic feature is characterised by aspecific inflammation (fragile mucosa with oedema, hyperhaemia, microhaemorrhagias or petechiae, superficial bleeding ulcerations) whereas the pseudomembranous lesions more classically found in adult patients are hardly detectable in children.

Among viral infections, pre-natal CMV assumes an important impact to the bowel (Fig. 16]. Other localisations can be possibly involved, including cerebral - ocular - hepatic and splenic localisations.

An involvement of the small bowel accompanying the rectal-colonic localisation can cause a severe intestinal malabsortion. A severe diarrhoea, often with bloody faeces, is clinically ob- 
served. Endoscopically, jeopardized micro-haemorrhages are seen, sometimes in association with lymphoid nodular hyperplasia.

Differential diagnoses including infections by HIV, atypical Mycobacteria, parasites (Giardia, Ameba, Schistosomes) and fungi, have to be considered in children with immune-depression.

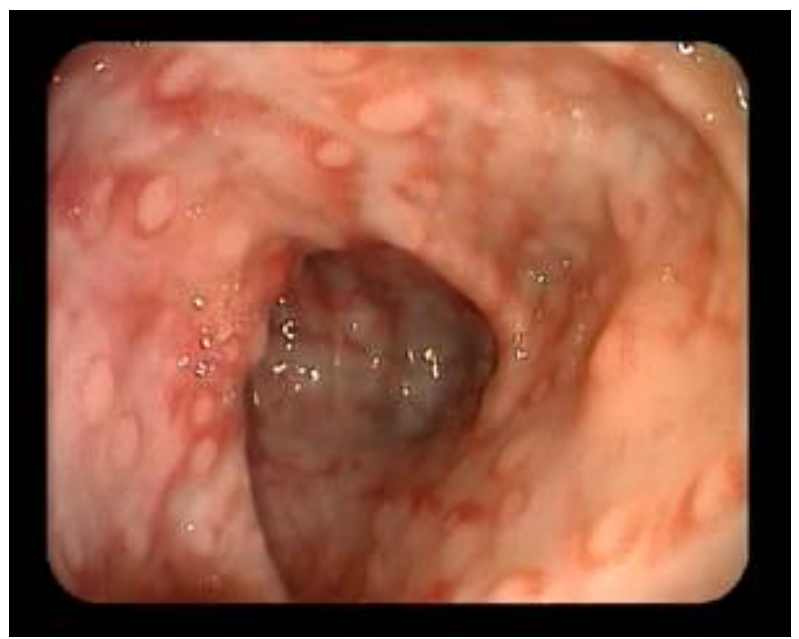

Figure 16. CMV related colitis in an immunodeficient infant

\subsection{Nodular Lymphoid Hyperplasia (NLH) of the Colon-Rectum [29]}

It is a very common feature in the paediatric age, in particular among newborns and toddlers. It is due to the presence of reactive hypertrophic lymphoid follicles. It is generally asymptomatic, but in some cases it can determine the appearance of bloody faeces. NLH can be related to allergic phenomena or can be expression of infective processes. In most of cases it is self-limiting and diminishes in the follow-up.

The endoscopic pattern is characterised by mucosal nodules with depressed tip (Fig. 17), sometimes associated with haemorrhage.

\subsection{Allergic Colitis [29]}

Colonic localisations of allergic processes in the child, are generally associated with the involvement of the upper GI segments or other organs. Allergic colitis clinically manifests with mucous bloody diarrhoea, and in those cases with important malabsorption it can determine major impairment of the general conditions. In the newborns and toddlers it is generally more frequent and related to vaccine milk proteins. 
The endoscopic aspect of the colonic mucosa is characterised by inflammation of the intestinal wall of variable extension, oedema, parietal necrosis, ulcerations and bleeding, nodular lymphoid hyperplasia (Fig. 18).

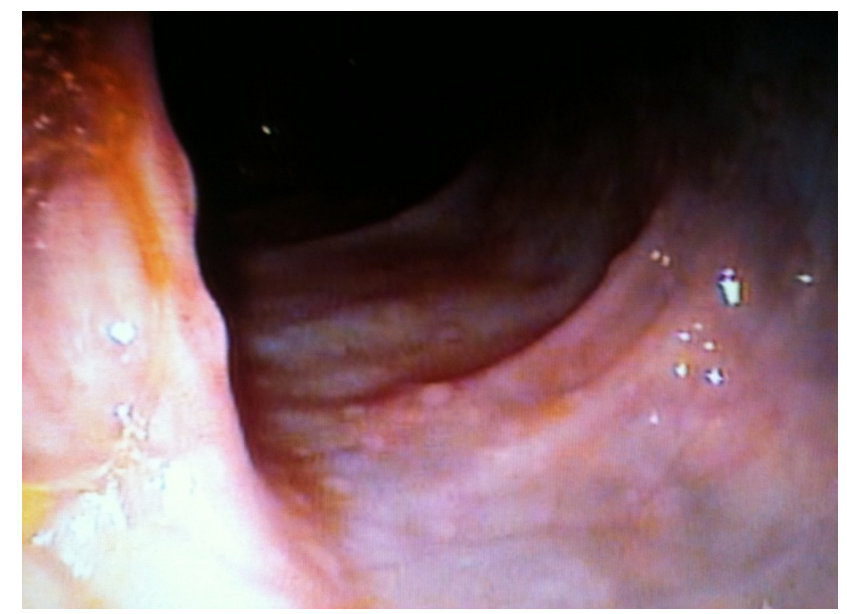

Figure 17. Lymphoid Nodular Hyperplasia of the colon

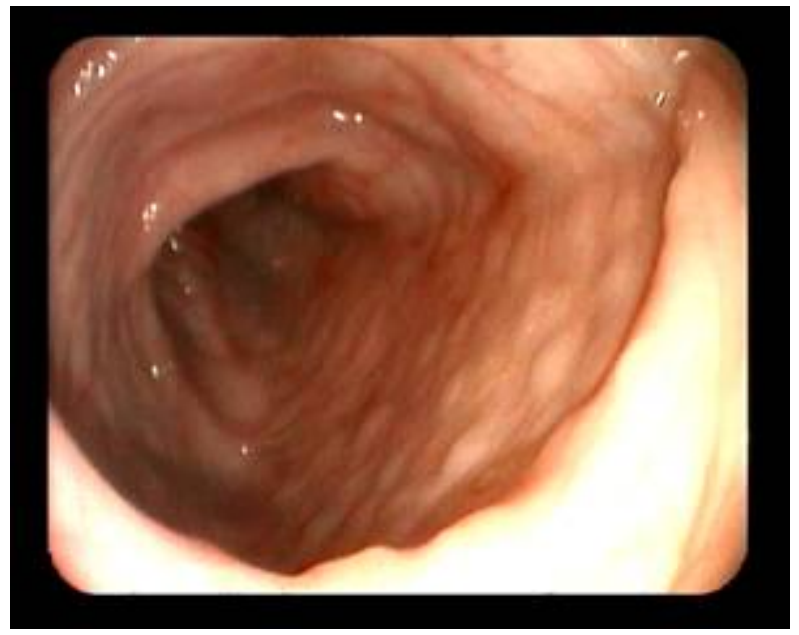

Figure 18. Allergic colitis in an infant 


\subsection{Inflammatory Bowel Disease [30-34]}

Endoscopy is able to differentiate Crohn's Disease (CD) and Ulcerative Colitis (UC) in 89\% of cases. It is, moreover, nowadays the most efficacious and diffused technique to evaluate CD localisation and activity at the level of terminal ileum and colon; its accuracy results, in fact, significantly superior with respect to bowel enema.

An immediate diagnosis with excellent accuracy is obtainable when endoscopy is associated to the histological examination of biopsy samples.

The endoscopic procedure for paediatric patients with IBD differs significantly from the modalities in use for the adults, especially as regards the use of sedation-analgesia, the number and localisation of the mucosal biopsies effectuated and the regular inclusion of terminal ileum intubation within a complete investigation.

In the paediatric age, assistance with anestesia allows to perform a complete endoscopic examination with visualisation of terminal ileum in $90 \%$ of cases.

The endoscopic evaluation of mucosal healing is important to identify the efficacy of a specific therapeutic regimen.

\subsection{Crohn's Disease [30-34]}

Endoscopic features in paediatric CD include aphthae (multiple, focal, surrounded by erythematosus mucosa; Fig. 19), nodules, serpiginous ulcers, cobblestone pattern of the intestinal mucosa and stenoses.

Inflammatory pseudopolips are less frequent in CD with respect to UC (Fig. 20).

According to the mucosal and phenotypical characteristics at onset, CD is classified into inflammatory, stenosing and fistulizing.

Since CD can potentially involves the whole gastrointestinal tract, the intubation of ileum and upper gastrointestinal endoscopy are always indicated for a complete staging of the disease.

At the level of the strictures, the intestinal mucosa usually appears actively inflamed, frequently ulcerated and bleeding.

In the fistulizing $C D$ phenotype, the internal orifice of the fistula can be observed on the bowel wall, generally in correspondence of inflamed areas.

The histological pattern of CD is generally characterised by transmural inflammation, dilatation and sclerosis of the lymphatic vessels, lymphoid aggregates and non caseating granuloma.

Oesophageal localisations can be found in patients with extended and severe Crohn's disease. The finding of granuloma at the histological exam of oesophageal biopsies needs firstly tuberculosis to be excluded. Secondarily, the effectuation of a lower endoscopy is mandatory. 


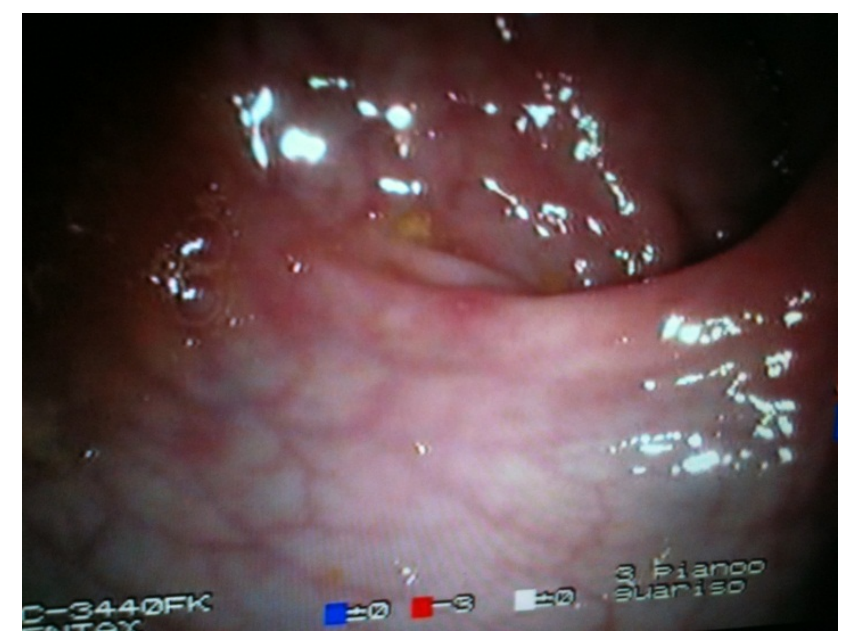

Figure 19. Crohn's Disease. Aphthae in the colonic mucosa

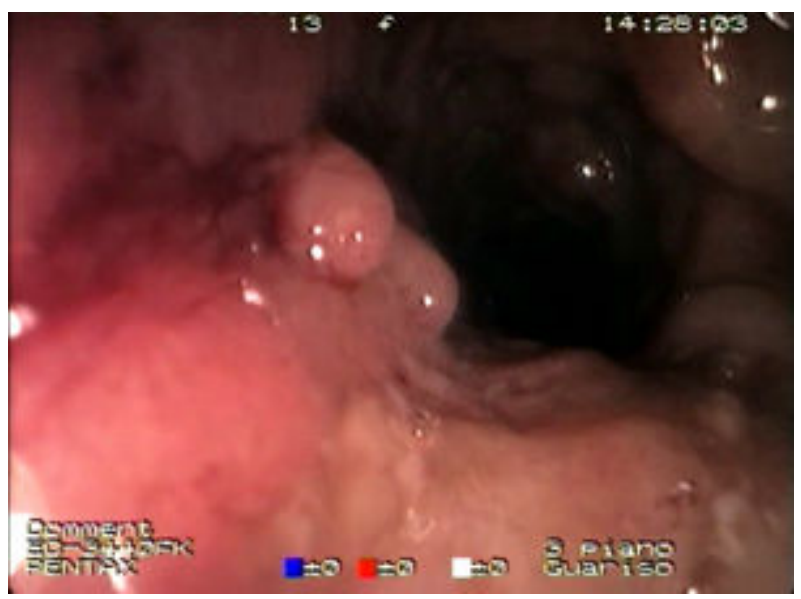

Figure 20. Colonic pseudoplyps in Ulcerative Colitis

\subsection{Ulcerative Colitis [30-34]}

Endoscopic features in paediatric UC include loss of normal vascular and architectural pattern, diffuse hyperhaemia, congestion, oedema, mucosal fragility and/or bleeding after contact with endoscope, mucous secretions, diffuse erosions covered by fibrin, ulcerations, aphthae, inflammatory pseudopolyps. 
Other possible findings include loss of colonic plicae with aspect of "rigid tube", backwash ileitis (ileal extension of lesions in pancolitis), patchy colitis and relative rectal sparing

Baron and Mayo are the two principal indexes for the endoscopic grading of Ulcerative Colitis.

The histological pattern in UC is characterised by distorsion and disappearance of the mucosal glands and cryptic inflammatory infiltration.

Also villi-like profile of the mucosal surface, a high grade alteration of the mucosal architecture, Paneth cells metaplasia and decrease of the inflammation and mucosal alteration grade from the upper to the lower colonic tract are seen.

\subsection{Gastrointestinal Polyps and Polyposis [35-37]}

Gastrointestinal polyps are macroscopically visible protrusions of the mucosal surface which can be classified in relation to their shape as sessile, pedunculated and plane polyps. A further histological classification distinguishes adenomatous, hyperplastic, inflammatory and hamartomatous polyps (Fig. 21).

In the paediatric age, intestinal polyps are generally represented by single juvenile polyps, and more rarely by familial polyposis.

Hyperplastic polyps are generally sessile and of small dimensions (2-5 $\mathrm{mm})$; they are formed by exceeding epithelial mature cells which do not separate from intestinal crypts and therefore cannot be lost in the intestinal lumen. A transformation into adenocarcinoma is attested in rare cases.

Adenomatous polyps are due to alterations in cellular proliferation and differentiation. They appear at endoscopy as sessile unique lesions, more rarely multiple, of small dimensions $(2-3 \mathrm{~cm})$; pedunculated and more dimensioned adenomatous polyps are more rarely found.

The covering mucosa is generally smooth and normally vascularised, with exception of bigger polyps in correspondence of which it can be hyperhaemic, spotted, lobular, ulcerated or with erosions. The histological examination of adenomatous polyps can show a tubular, villous or intermediate patterns. Adenomatous polyps are dysplastic lesions which are differentiated into mild, moderate or severe according to the relating risk of carcinomatous degeneration.

Juvenile polyps are the most frequently observed in the paediatric age $(90 \%)$ and are generally isolated, exceptionally multiple and under a maximum number of 8 . They are histologically characterised by an excessive development of lamina propria including crypts with cystic dilatation. The endoscopic aspect is pedunculated, roundish, with a smooth surface and a typical diameter of $1-1.5 \mathrm{~cm}$ (Fig. 22). A superficial ulceration and cellular inflammation are frequently found on the polyp, with regenerative epithelial hyperplasia. $70 \%$ of juvenile polyps are localised at rectum and $15 \%$ at sigma. No ileal localisations are possible. The clinical presentation is characterised by small persistent haemorrhagias, which is rarely severe to cause anemia. Associated abdominal pain is frequently observed. Alternated intestinal transit and mild diarrheal represent other possible associated clinical features. 
Rectal polyps with huge dimensions can determine mucosal prolapse. Juvenile polyps are not associated with increased risk of carcinomatous transformation.

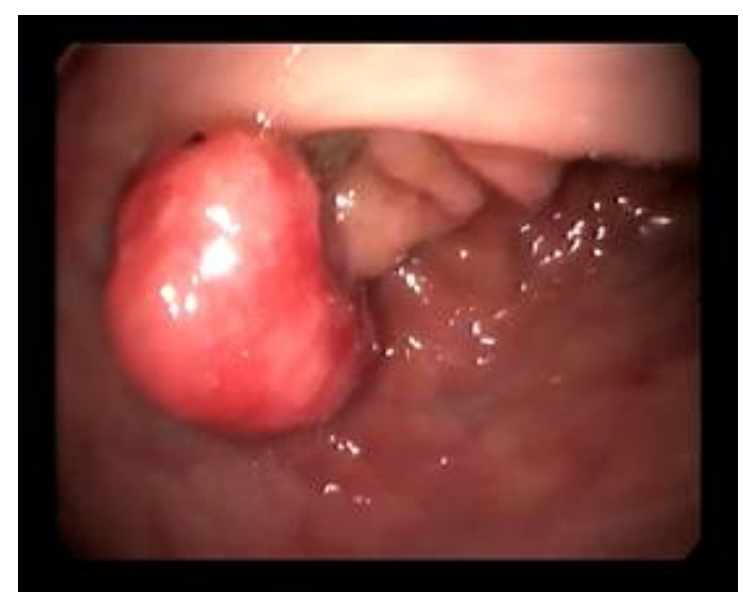

Figure 21. Hamartomatous polyp of the colon

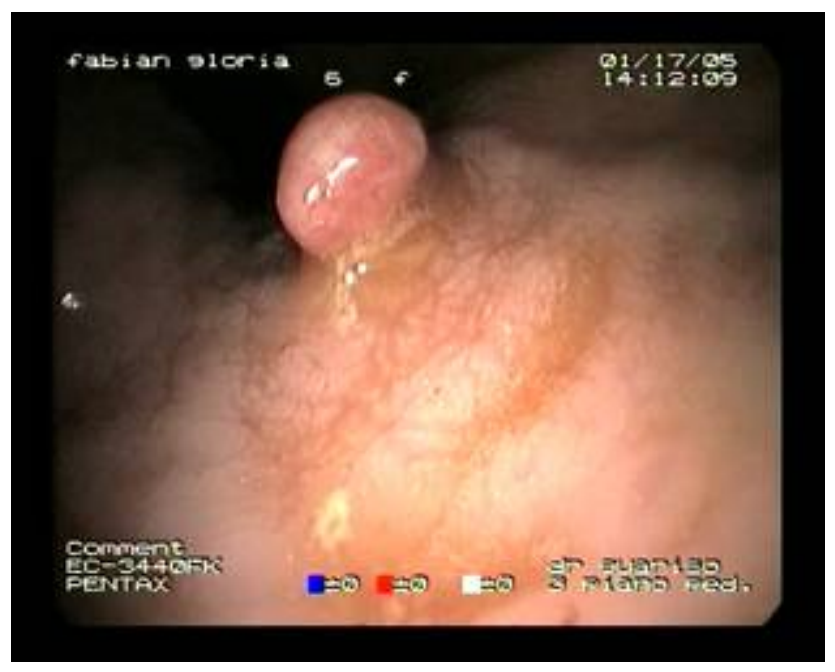

Figure 22. Juvenile rectal polyp

Principal Familial Polyposis

Familial Adenomatous Polyposis (FAP) is a disease with autosomal dominant transmimission, characterised by the formation of multiple adenomatous polyps (> 100) which can involve 
every GI segment, mainly the colon-rectum but also the stomach and the small bowel. Multiple extraintestinal manifestation can be associated.

The risk of neoplastic degeneration with time is of $100 \%$. In $30 \%$ of cases there is no familiarity for the disease, so a spontaneous spot mutation is involved. The disease incidence is of 1/8.000-10.000 newborns. The responsible gene (APC) has been identified in the $5 \mathrm{q}$ 21-22 region and is a "tumor suppressor gene" which encodes a protein involved in the mechanisms of intercellular connection and transmission. More than 200 mutations have been identified at present, to which disease phenotypes with different severity correspond.

A pre-symptomatic disease diagnosis as well as the development of surveillance protocols are fundamental before the disease manifests.

Polyps are not present at birth, but usually develop within the first years of life, mainly in correspondence with puberty: this suggests that other factors than genetics intervene in the manifestation of disease.

According to their degree of development, polyps can present different dimensions, shapes (plane, pedunculated or sessile), and with different histological pattern (tubular, villous, intermediate).

Gastric polyps are generally glandular and localised at the gastric fundus; antral adenoma are less frequent. At the duodenum, the risk of adenoma and adenocarcinoma at the Vater papilla is high.

The main clinical symptom is characterised by bloody faeces, both as a massive bleeding and as occult bleeding leading progressively to anemia. Intestinal intussusception or anal polyp prolapse are also possible, especially in infants. Recurrent abdominal pain is also a common symptom.

Diarrhoea, electrolytic alterations and protein-loosing enteropathy are potential consequences of an elevated number of polyps.

Screening for FAP includes faecal occult blood research, endoscopic surveillance and genetic techniques.

A number of extraintestinal manifestations can be variably attested, the most common one being an ocular disease with multiple bilateral pigmented lesions which are secondary to a hypertrophy of retinal epithelium (CHRPE). An accurate ophthalmologic exam is therefore fundamental in at-risk children.

A common FAP related manifestation is the development of desmoid tumors which is observed in $9-32 \%$ of patients: these are mesenchymal benign tumors originating from mesenter and peritoneum, and which can cause compressive phenomena on abdominal organs and on vases.

Neoplasia at the level of thyroid, pancreas, adrenal glands, urinary bladder, testicles, lipomas, myomas, fibromas and hepatoblastomas have also been found in association.

Gardner Syndrome is an autosomal dominant variant of FAP, the relative mutated gene being APC as well. This syndrome differentiates from FAP in terms of extraintestinal manifesta- 
tions: in $90 \%$ of patients osteomas are observed, with localisation at teeth, jaw, other facial bones, long bones of legs and pelvis.

Over-numbered teeth and multiple tooth caries can be also associated. Desmoid tumors involve about $15-20 \%$ of affected patients.

Turcot Syndrome is a rare recessive disease, characterised by an early onset appearance of cerebral and medullar tumors in infants (glioblastomas, astrocytomas and medulloblastomas) which generally anticipate intestinal adenoma and condition the survival rate of affected patients.

Colonic adenoma evolve to cancers within the second-third decade of life.

Ruvalcaba-Myhre-Smith Syndrome is a FAP variant related to an alteration of a gene with localisation at 10q23. It is characterised by a colonic and ileal hamartomatous polyposis and associated with mental retardation, myopathy, cranial and facial dysmorphisms, macrocephaly, skeletal abnormalities and genital stains.

Peutz-Jeghers (PJS) is an autosomal dominant hereditary polyposis with a variable grade of penetration [40-50\%). The mutate gene is the oncogene STK11 (19p 13.3). The distinctive elements of the syndrome are skin and mucosal pigmentation especially at the level of mouth and genitals, as well as the development of hamartomatous polyps.

Polyps can be found from stomach to anus, but their most frequent localisation is at the small bowel, especially at the jejunum and ileum. Their number is lower than in FAP, and the polyp shape also spreads from small sessile polyps to large pedunculated elements. Their histological nature is hamartomatous.

The clinical onset generally dates before adolescence, and is generally characterised by variable symptoms including recurrent abdominal pain, diarrhoea, occult bleeding, haematic faeces, intestinal obstructions or intussusceptions. Hyperpigmented (bluish-black coloured) stains are localised at the skin and mucosa of lips, cheeks, nasal orifices, eyes, genital and perianal region, hands and feet.

While skin stains can disappear, mucosal lesions are generally permanent.There are subjects who never develop skin nor mucosal stains.

An increased risk for intestinal cancers is attested in these patients, especially adenocarcinoma of jejunum and ileum. Extraintestinal manifestations include cancers at breast, uterine cervix, ovaries, testicular Sertoli's cells and thyroid. Bronchial adenomas, nasal polyps, hepatic hamartoma, pancreatic and gallbladder tumors are also possible.

Specific screening programs are therefore mandatory for PJS patients.

Cowden Syndrome is anautosomal dominant hereditary polyposis, characterised by hamartomatous lesions of ectodermal, mesodermal and endodermal origin. The responsible germinal-line mutations involve the PTEN gene (10q23) in $80 \%$ of cases, encoding a tyrosine phosphatase.

Clinical manifestations generally date at the second-third decade of life, even though earlier onsets are also possible. Abdominal pain and gastrointestinal bleeding represent the main 
clinical features. Polyps are generally localised at the distal colonic segments (Fig. 23). The distinctive elements of the syndrome are the skin and mucosal lesions comprehending oral papilloma, facial hamartoma and localisations at the extremities of the limbs. Narrow palate, macrocephaly and scoliosis are often found.

Benign tumors of soft tissues are common, including lipomas, angiomas and fibromas.

Malignant extraintestinal complications include breast cancer and thyroid neoplasias.

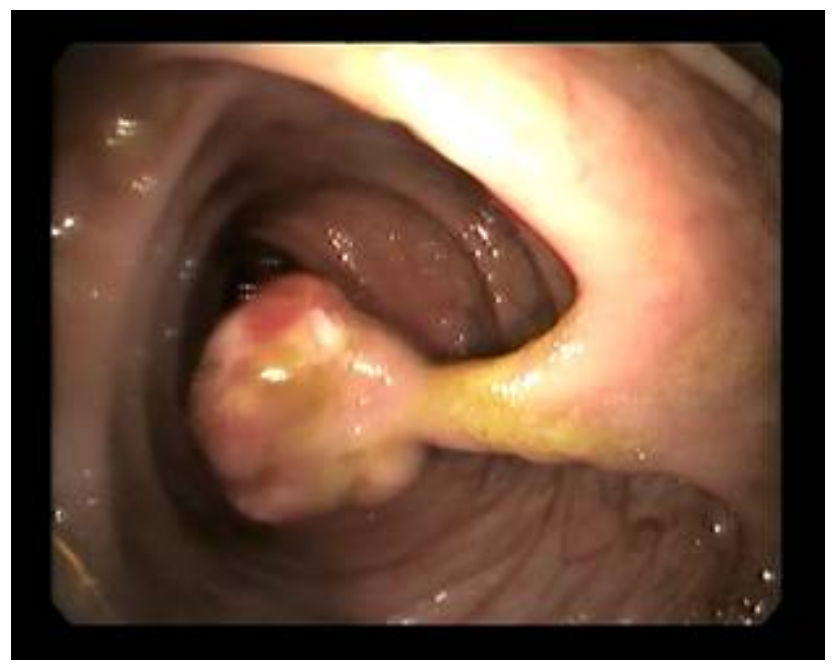

Figure 23. Polyp of the colon in Cowden Syndrome

\section{Approach to children with hereditary gastrointestinal polyposis [35-36]}

An accurate familial anamnesis is the first fundamental step, even though cases of spontaneous mutations [30\% of FAP and PJS) are also described.

A careful clinical examination is important, especially for detection of peculiar extra-intestinal manifestations, i.e. skin and mucosal lesions in PJS, the ophthalmologic evaluation in FAP and the dental and facial bone alterations in Gardner Syndrome.

Blood tests have a role in detecting the degree of affection of general conditions, in particular the detection of anaemia. Haematic tests for liver, kidney and muscles need also to be checked as well as electrolytes and the inflammation indexes.

Genetic tests on peripheral blood lymphocytes are possible for FAP (i.e. linkage test with accuracy of $95 \%)$.

A genetic counselling needs to be considered before performing any genetic test for screening and diagnosis of polyposic syndromes. In fact, no single test is associated with a suffi- 
cient accuracy for the diagnosis of GI polyposis and more genetic alterations are usually coexisting in a single patient.

Children are generally genetically tested after 10 years of age, before the activation of an endoscopic surveillance, and once they are able to understand the implications of the diagnostic tests performed.

The fundamental priority is to characterise with the highest accuracy, the number, localisation and histological nature of the GI polyps.

Upper and lower endoscopies represent the pivotal diagnostic procedures for GI polyposes. Bioptic samples need to be taken for the histological examination of lesions and the exclusion of a malignant transformation. A collaboration between physicians and pathologists is fundamental for the diagnosis and therapeutic management of polyposes.

The performance of endoscopic polypectomies is a therapeutic option which can be considered in addition to the diagnostic role of US, CT and MRN in the detection of extraintestinal manifestations and metastases as well as in the study of those GI segment which cannot be explored with endoscopy.

Wireless capsule endoscopy permits a complete visualisation of the small bowel but does not consent the collection of bioptic samples. Barium enhanced radiologic techniques represent a less accurate and less invasive alternative for the investigation of small bowel lesions.

Polypetomy is a technique performed under sedation in children. A well conducted colonic preparation and a control of coagulation indexes are mandatory before its performance. The polyp excision is performed with a dyatermic loop.

The loop shape and kind is chosen according to the dimensional characteristics and to the localisation of the polyp.

The removed polyp will then be recuperated with a loop or with Dormia basket.

In cases of multiple polyposes, the eradications of polyps can be effectuated in repeated times.

The procedure of polypectomy results to be more feasible at the level of the stomach and duodenum with respect to colonic localisations, for technical reasons.

Potential complications of polypectomy include haemorrhage and perforation (variable incidence of $0.4-4 \%$ )

Surgical interventions of intestinal resections are indicated in subjects with FAP and comprehend total colectomy and ileal-rectal anastomosis or procto-colectomy with ileal-anal anastomosis and ileal pouch.

A multidisciplinary approach generally offers better results for patients with polyposis syndromes. Affected children should be cared by a team including a paediatric gastroenterologist, a genetist, a surgeon and a paediatric psychologist. 
Several studies have demonstrated the importance of regional and national registers, aimed to a screening for neoplasia and to the identification of high risk relatives. These screening protocols have significantly reduced the morbidity and mortality associated to these illnesses.

\section{Author details}

Marco Gasparetto and Graziella Guariso

Department of Woman and Child Health, Unit of Gastroenterology, Digestive Endoscopy, Hepatology and Care of the Child with Liver Transplantation, University Hospital of Padova, Italy

\section{References}

[1] Squires RH Jr, Colletti RB. Indications for pediatric gastrointestinal endoscopy: a medical position statement of the North American Society for Paediatric Gastroenterology and Nutrition. J Pediatr Gastroenterol Nutr 1996;23(2): 107-10.

[2] Brook RH, Chassin MR, Fink A, Solomon DH, Kosecoff J, Park RE. A method for the detailed assessment of the appropriateness of medical technologies. Int J Technol Assess Health Care 1986;2(1):53-63.

[3] Guariso G, Meneghel A, Dalla Pozza L, et al. Indications to upper gastrointestinal endoscopy in children with dyspepsia. J Pediatr Gastroenterol Nutr 2010;50(5):493-9.

[4] De Angelis GL, Papparella A, Fornarioli F, and Torroni F. Cenni di Tecnica Endoscopica. In: L'endoscopia Digestiva in Età Pediatrica e Giovanile. De Angelis GL eds EMSI Roma 2002, pp 27-30.

[5] Van Beek EJ, Leroy PL. Safe and effective procedural sedation for gastro-intestinal endoscopy in children: a systematic review. J Pediatr Gastroenterol Nutr 2012;54(2): 171-85.

[6] Baruch K, Steven MG. Sedation and analgesia for procedures in children. N Engl J Med 2000; 342: 938-945.

[7] American Accademy of Pediatrics, Committee on Drugs. Guidelines for monitoring and management of pediatric patients during and after sedation for diagnostic and therapeutic procedures. Pediatrics 1992; 89: 1110-5.

[8] Meyer S, Grundmann U, Gottshling S, et al. Sedation and analgesia for brief diagnostic and therapeutic procedures in children. Eur J Pediatr 2007; 166: 291-302. 
[9] Da Silva MM, Briars GL, Patrick MK, Cleghorn GJ, Shepherd RW. Colonoscopy preparation in children: safety, efficacy, and tolerance of high- versus low-volume cleansing methods. J Pediatr Gastroenterol Nutr 1997; 24(1):33-7.

[10] Hassal E. Risk of oral sodium phosphate for precolonoscopy bowel preparation in children. Dis Colon Rectum 2007; 50: 1099-1103.

[11] Loening-Baucke V, Krishna R, Pashankar DS. Polyethylene glycol 3350 without electrolytes for the treatment of functional constipation in infants and toddlers. J Pediatr Gastroenterol Nutr 2004; 39(5): 536-9.

[12] Dahshan A et al. A randomized, prospecitve study to evaluate the efficacy and acceptance of three bowel preparations for colonoscopy in children. Am J Gastroenterol 1999; 94: 3497-501.

[13] Gremse DA, Sacks AI, Raines S. Comparison of oral sodium phosphate to polyethylene glycol-based solution for bowel preparation for colonoscopy in children. J Pediatr Gastroenterol Nutr 1996; 23(5): 586-90.

[14] Wyllie R, Kay MH. Gastrointestinal endoscopy in infants and children. Pediatr Rev 1993; 14(9): 352-9.

[15] De Angelis GL, Bizzarri B, De Angelis N, Borrelli O: La diagnostica endoscopica. Consensus Statement SIGENP: Malattie Infiammatorie Croniche Intestinali in età pediatrica 2008; pp 23-26.

[16] Orenstein SR. Management of supraesophageal complications of gastroesophageal reflux disease in infants and children. Am J Med 2000, 108(Suppl): 139-43.

[17] Lundell LR, Dent J, Bennett JR, Blum AL, Armstrong D, Galmiche J-P et al. Endoscopic assessment of oesophagitis: clinical and functional correlates and further validation of the Los Angeles classification. Gut 1999;45:172-180.

[18] De Angelis GL, Torroni F, Bizzarri B, Manfredi M. La patologia esofagea. In: L'endoscopia Digestiva in Età Pediatrica e Giovanile. De Angelis GL eds EMSI Roma 2002, pp 37-47.

[19] Meneghel A, Zulian F, Martini G, Guariso G. Ischemic ulcerative colitis in juvenile dermatomyositis. J Pediatr Gastroenterol Nutr 2009; 49(5): 549.

[20] Walsh SV, Antonioli DA, Goldman H, et al. Allergic esophagitis in children: a clinicopathological entity. Am J Surg Pathol 1999; 23(4): 390-6.

[21] Kleinman R, Goulet OJ, Mieli-Vergani G, Sanderson I, Sherman P, Shneider B. Treatment of End-Stage Liver Disease. Walker's Pediatric Gastrointetsinal Disease, $5^{\text {th }}$ Edition. Volume 2, Chapter 38: 1133-48.

[22] De Giacomo C, Bacchini PL, Lombardi M, De Angelis GL. La patologia gastrica. In: L'endoscopia Digestiva in Età Pediatrica e Giovanile. De Angelis GL eds EMSI Roma 2002, pp 49-68. 
[23] Blecker U, Gold BD. Gastritis and peptic ulcer disease in childhood. Eur J Pediatr 1999; 158(7): 541-6.

[24] Imrie C, Rowland M, Bourke B, et al. Is Helicobacter Pylori infection in childhood a risk factor for gastric cancer? Paediatrics 2001; 107(2): 373-80.

[25] Heldwein W, Schreiner J, Pedrazzoli J, Lehnert P. Is the Forrestclassification a useful tool for planning endoscopic therapy of bleeding peptic ulcers? Endoscopy 1989 Nov;21(6):258-62.

[26] Gupta SK, et al. Is esophagogastroduodenoscopy necessary in all caustic ingestions? J Pediatr Gastroenterology Nutr 2001; 32: 50-53

[27] Kay M, Wyllie R. Caustic ingestions and the role of endoscopy. J Pediatr gastroenterol Nutr 2001; 32: 8-10.

[28] Husby S, Koletzko S, Korponay-Szabò IR, Mearin ML, Philips A, Shamir R, Troncone R, Giersiepen K, Branski D, Catassi C, Lelgeman M, Maki M, Ribes-Koninckx C, Ventura A, Zimmer KP. (ESPGHAN Working Group on Coeliac Disease Diagnosis).ESPGHAN Guidelines for the diagnosis of coeliac disease in children and adolescents. An evidence-based approach. In Press. 2012.

[29] De Angelis GL, Bacchini PL, Romano C, Cucchiara S. La patologia del colon. In: L'endoscopia Digestiva in Età Pediatrica e Giovanile. De Angelis GL eds EMSI Roma 2002, pp 81-91.

[30] Venkatesh K, Thomson M. Endoscopic Modalities in Pediatric Inflammatory Bowel Disease. In: Pediatric Inflammatory Bowel Diseases. Mamula P, Markowitz JE, Baldassano RN eds Springer Publ New York 2008, pp 211-35.

[31] Bourreille A et al. Role of small-bowel endoscopy in IBD: international OMED-ECCO consensus. Endoscopy 2009; 41: 618-637

[32] Venkatesh K, Thomson M. Endoscopic Modalities in Pediatric Inflammatory Bowel Disease. In: Pediatric Inflammatory Bowel Diseases. Mamula P, Markowitz JE, Baldassano RN eds Springer Publ New York 2008, pp 211-35.

[33] Venkatesh K, Thomson M. Endoscopic Modalities in Pediatric Inflammatory Bowel Disease. In: Pediatric Inflammatory Bowel Diseases. Perspectives and Consequences. Walker-Smith JA, Lebenthal E, Branski D eds Karger Publ Basel Switzerland 2009, pp 100-122.

[34] Gasparetto M, Guariso G. Endoscopy in Paediatric Inflammatory Bowel Disease (IBD). In: Gastrointestinal Endoscopy. Pascu O eds INTECH 2011, pp 237-253.

[35] Gupta SK, Fitzgerald JF. Experience with juvenile polyps in North American children: the need for pancolonoscopy. Am J Gastroenterolo 2001; 96(6): 1695-7.

[36] Olschwang S. Digestive polyposes: genetic aspects. Gastroenterol Clin Biol 2001; 25(Suppl): B26-30. 
[37] Salviati L, Patricelli M, Guariso G, Sturniolo GC, Alaggio R, Bernardi F, et al. Deletion of PTEN and BMPR1A in chromosome 10q23 is not always associated with juvenile polyposis of infancy. Am J Hum Genet 2006; 79(3): 593-6. 